\title{
Internal Repair of Gas Pipelines Survey of Operator Experience and Industry Needs Report
}

\author{
Reporting Period: \\ June 30, 2003 through August 31, 2003
}

Principal Author:

Ian D. Harris

Report Issued: September 2003

Revised: N/A

Revision \#0

DOE Award No.: DE-FC26-02NT41633

Submitted By:

Edison Welding Institute

1250 Arthur E. Adams Drive

Columbus, $\mathrm{OH} 43221$

Significant Subcontractor:

Pacific Gas \& Electric

3400 Crow Canyon Road

San Ramon, CA 94583 


\section{DISCLAIMER}

This report was prepared as an account of work sponsored by an agency of the United States Government. Neither the United States Government nor any agency thereof, nor any of their employees, makes any warranty, express or implied, or assumes any legal liability or responsibility for the accuracy, completeness, or usefulness of any information, apparatus, product, or process disclosed or represents that its use would not infringe privately owned rights. Reference herein to otherwise does not necessarily constitute or imply its endorsement, recommendation, or favoring by the United States Government or any agency thereof. The views and opinions of authors expressed herein do not necessarily state or reflect those of the United States Government or any agency hereof.

Measurement Units -- SI Metric System of Units are the primary units of measure for this report followed by their U.S. Customary Equivalents in parentheses ( ).

Note: SI is an abbreviation for Le Systeme International d'Unites." 


\begin{abstract}
A repair method that can be applied from the inside of a gas transmission pipeline (i.e., a trenchless repair) is an attractive alternative to conventional repair methods since the need to excavate the pipeline is precluded. This is particularly true for pipelines in environmentally sensitive and highly populated areas.
\end{abstract}

The objectives of the project are to evaluate, develop, demonstrate, and validate internal repair methods for pipelines; develop a functional specification for an internal pipeline repair system; and prepare a recommended practice for internal repair of pipelines. The purpose of this survey is to better understand the needs and performance requirements of the natural gas transmission industry regarding internal repair.

A total of fifty-six surveys were sent to pipeline operators. A total of twenty completed surveys were returned, representing a $36 \%$ response rate, which is considered very good given the fact that tailored surveys are known in the marketing industry to seldom attract more than a $10 \%$ response rate.

The twenty survey responses produced the following principal conclusions:

1. Use of internal weld repair is most attractive for river crossings, under other bodies of water (e.g., lakes and swamps) in difficult soil conditions, under highways, under congested intersections, and under railway crossings. All these areas tend to be very difficult and very costly if, and where, conventional excavated repairs may be currently used.

2. Internal pipe repair offers a strong potential advantage to the high cost of horizontal direct drilling (HDD) when a new bore must be created to solve a leak or other problem in a water/river crossing.

3. The typical travel distances required can be divided into three distinct groups: up to $305 \mathrm{~m}$

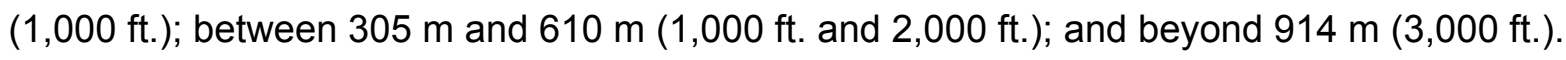
In concept, these groups require pig-based systems; despooled umbilical systems could be considered for the first two groups. For the last group a self-propelled system with an onboard self-contained power and welding system is required.

4. Pipe size range requirements range from $50.8 \mathrm{~mm}$ (2 in.) through 1,219.2 mm (48 in.) in diameter. The most common size range for $80 \%$ to $90 \%$ of operators surveyed is $508 \mathrm{~mm}$ to $762 \mathrm{~mm}$ (20 in. to $30 \mathrm{in}$.) diameter, with $95 \%$ using $558.8 \mathrm{~mm}$ (22 in.) diameter pipe. 


\section{TABLE OF CONTENTS}

Page

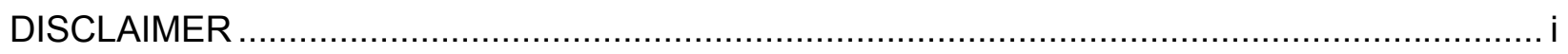

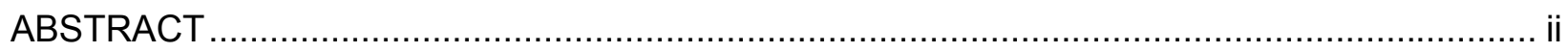

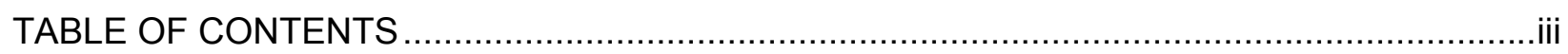

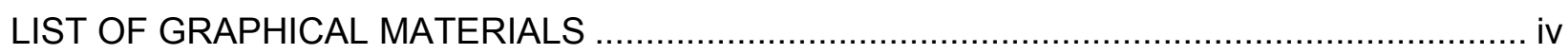

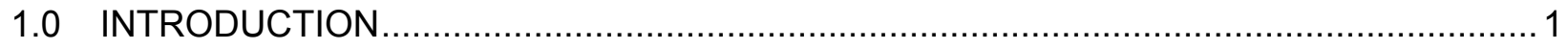

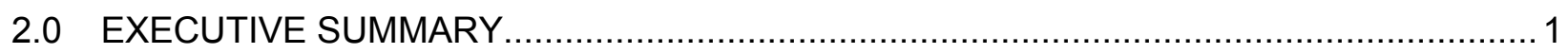

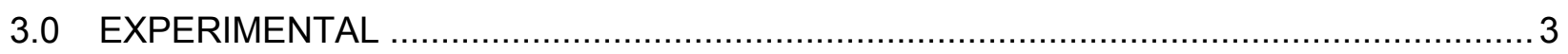

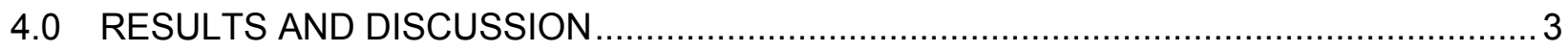

Part 1 - Currently-Used Repair Methods ................................................................ 5

Part 2 - Use/Potential Use of Internal Repair ........................................................ 9

Part 3 - Need for In-Service Internal Repair .............................................................. 15

Part 4 - Applicable Types of Damage ..................................................................... 18

Part 5 - Operational and Performance Requirements for Internal Repairs ........................20

Part 6 - General Comments ........................................................................... 23

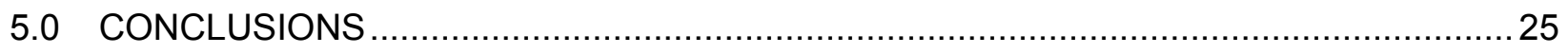

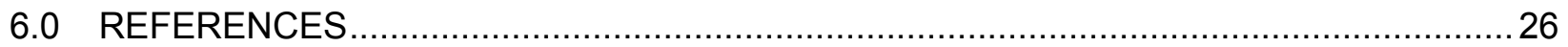

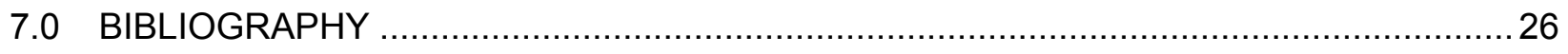

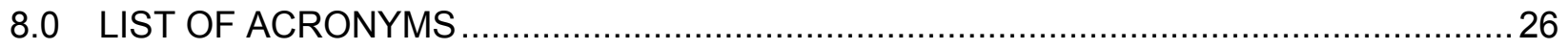

APPENDIX A - SURVEY AND COVER LETTER ..................................................... A-1

APPENDIX B - LISTS OF PRCI MEMBERS \& OTHER GAS COMPANIES .......................... B-1 


\section{LIST OF GRAPHICAL MATERIALS}

$\underline{\text { Page }}$

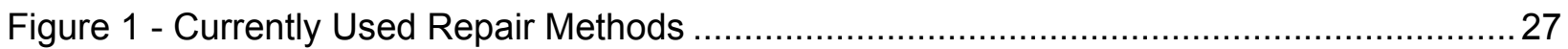

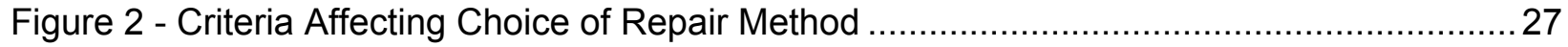

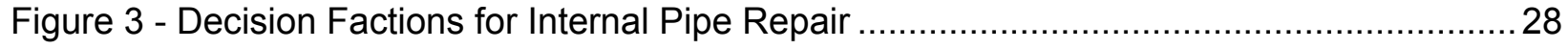

Figure 4 - Specific Geographic Locations and Special Situations ........................................2 28

Figure 5 - Distance Repair System Required to Travel Down Pipe .....................................29

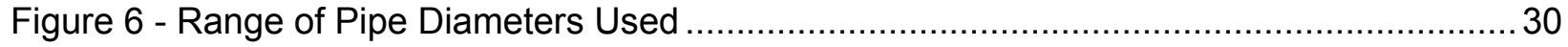

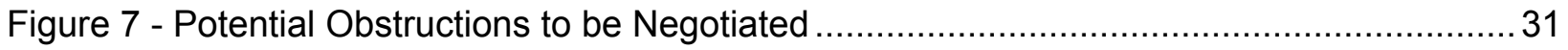

Figure 8 - Cost Comparative Breakpoint for Internal Repair ................................................ 31

Figure 9 - Estimated Number of Internal Repairs Required Per Year..................................... 32

Figure 10 - Importance of Repair While Pipeline Remains In Service .................................. 32

Figure 11 - Still Attractive if Pipeline Must be Shut Down (Depressurized and Evacuated) ........ 33

Figure 12 - Still Attractive if Pipeline Must be Depressurized but Not Evacuated......................33

Figure 13 - Still Attractive if Pipeline Must be Out of Service but Pressurized......................... 34

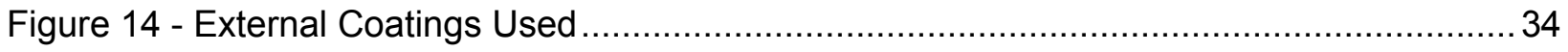

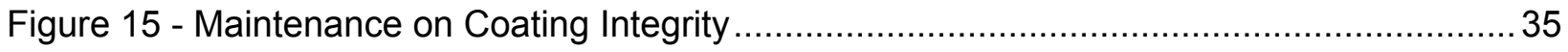

Figure 16 - Is CP System Capable of Compensating for Small Coating Breaches.....................35

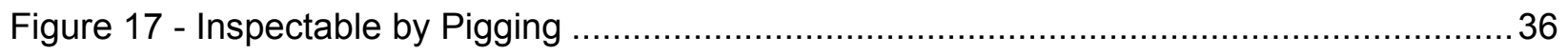

Figure 18 - How Far Could the Repair Protrude Into Pipe Before Interference ........................ 36

Figure 19 - NDE Required for Repair to an Existing Weld ............................................... 37

Figure 20 - NDE Required for Base Metal Repair ...................................................... 37

Figure 21 - Would Internal Repair be Attractive Even as a Temporary Repair? ...................... 38 


\subsection{INTRODUCTION}

A repair method that can be applied from the inside of a gas transmission pipeline (i.e., a trenchless repair) is an attractive alternative to conventional repair methods since the need to excavate the pipeline is precluded. This is particularly true for pipelines in environmentally sensitive and highly populated areas. Several repair methods that are commonly applied from the outside of the pipeline are, in theory, directly applicable from the inside. However, issues such as development of the required equipment to perform repairs remotely and mobilization of equipment through the pipeline to areas that require repair need to be addressed. Several additional repair methods that are commonly applied to other types of pipelines (e.g. gas distribution lines, water lines, etc.) also have potential applicability for internal repair of gas transmission pipelines. Many of these require further development to meet the requirements for repair of gas transmission pipelines. The objectives of the project are to evaluate, develop, demonstrate, and validate internal repair methods for pipelines; develop a functional specification for an internal pipeline repair system; and prepare a recommended practice for internal repair of pipelines. The purpose of this survey was to better understand the needs and performance requirements of the natural gas transmission industry regarding internal repair.

\subsection{EXECUTIVE SUMMARY}

A repair method that can be applied from the inside of a gas transmission pipeline (i.e., a trenchless repair) is an attractive alternative to conventional repair methods since the need to excavate the pipeline is precluded. This is particularly true for pipelines in environmentally sensitive and highly populated areas.

The objectives of the project are to evaluate, develop, demonstrate, and validate internal repair methods for pipelines; develop a functional specification for an internal pipeline repair system; and prepare a recommended practice for internal repair of pipelines. The purpose of this survey was to better understand the needs and performance requirements of the natural gas transmission industry regarding internal repair.

A total of fifty-six surveys were sent to pipeline operators. A total of twenty completed surveys were returned, representing a $36 \%$ response rate, which is considered very good given the fact that tailored surveys are known in the marketing industry to seldom attract more than a $10 \%$ response rate. 
The twenty survey responses produced the following conclusions:

1. Use of internal weld repair is most attractive for river crossings, under other bodies of water such as lakes and swamps, in difficult soil conditions, under highways and in congested intersections, and under railway crossings. All these areas tend to be very difficult and very costly, if, and where conventional excavated repairs may be currently used.

2. Internal pipe repair offers a strong potential advantage to the high cost of HDD when a new bore must be created to solve a leak or other problem in a water/river crossing.

3. The typical travel distances required can be divided into three distinct groups: up to $305 \mathrm{~m}$

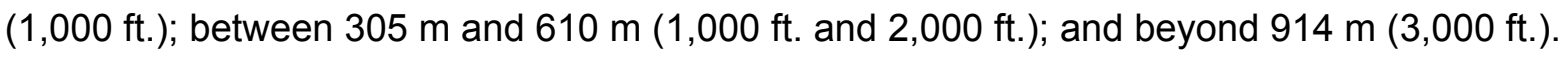
In concept, all these systems would be pig-based. Systems with despooled umbilicals could be considered for the first two groups. For the last group a self-propelled system with an onboard self-contained power and welding system is required.

4. Pipe size range requirements range from $51 \mathrm{~mm}(2 \mathrm{in.})$ through $1,219 \mathrm{~mm}$ (48 in.) in diameter. The most common size range for $80 \%$ to $90 \%$ of operators surveyed is $508 \mathrm{~mm}$ to $762 \mathrm{~mm}$ (20 in. to 30 in.) diameter, with 95\% using $559 \mathrm{~mm}$ (22 in.) diameter pipe.

5. Based on the frequency of expected use by many operators, the issue of acceptable system cost for a deployable solution could best be tackled through selling such technology as an additional service through existing "smart pig" vendors/operators.

6. There has been almost no use of internal repair to date and the concept is currently fairly alien to pipeline operators. Even the potential for internal repair of external damage using such a system needs further promotion/education within the industry as a whole.

7. Most operators were open to the economic potential an internal repair system may offer in terms of reducing interruption to product flow, particularly if they did not have looped lines.

8. The top three items of concern for selecting a repair method were cost, availability of the repair method (time/cost), and the position of the defect(s).

9. A wide range of pipe coatings were cited as being deployed in the field. The top three mentioned were fusion bonded epoxy (FBE), coal tar, and concrete/POWERCRETE®.

10. The majority of operators considered the ability for the pipeline to remain in service while the repair was conducted to be very important.

11. Radiographic testing (RT) is by far the most accepted method for pipeline nondestructive evaluation (NDE). Ultrasonic testing (UT) was the second most common process cited. 


\subsection{EXPERIMENTAL}

This part of the project was a survey and so did not involve an experimental procedure or equipment in the conventional sense.

\section{Survey Development}

The survey (Appendix A) was sent to a wide range of gas transmission companies, both member companies of the Pipeline Research Council International (PRCI), and also to other companies within the industry (Appendix B). The list of contacts was built up from the PRCI Materials Committee Roster, a list of other gas companies from the http://www.ferc./gov/gas companies/pipelines web site, and a web-based list of gas company executives, in addition to personal contacts within the industry. An extensive series of phone calls were made to establish the most appropriate person or persons at each company to whom to send the survey, and to establish whether a central point of contact (POC) or multiple recipients was preferred. In most cases, the appropriate staff member at parent companies with several pipeline subsidiaries preferred to be a central POC, gathering this and sending the feedback to EWI through one survey for their company.

Email addresses were gathered for all the survey recipients such that the survey could be sent, completed, and returned, electronically.

\subsection{RESULTS AND DISCUSSION}

A total of fifty-six surveys were sent out mostly to the single main identified POC at each company. In two cases, three surveys were sent to individuals within a single company. A total of twenty completed surveys were returned, representing a $36 \%$ response rate. Four additional companies responded that they did not plan to complete the survey, due to construction or other time pressures. The response rate of $36 \%$ is considered very good given the fact that tailored surveys are known in the marketing industry to seldom attract more than a $10 \%$ response rate. 
The following companies responded to the survey:

CenterPoint Energy

- Mississippi River Transmission System

Reliant Energy Gas Transmission System

El Paso Corporation

- ANR Pipeline Company

ANR Storage Company

- Blue Lake Gas Storage Company

- Colorado Interstate Gas Company

El Paso Natural Gas Company

El Paso Field Services

EPGT Texas Pipeline, LP

- Gulf States Transmission Company

- High Island Offshore System

- Mojave Pipeline Company

- Petal Gas Storage Company

- Southern Natural Gas Company

- Tennessee Gas Pipeline Company

- Wyoming Interstate Company, Ltd.

Young Gas Storage Company, Ltd.

Dominion Transmission, Inc.

Duke Energy Gas Transmission

- Algonquin Gas Transmission Company

Algonquin LNG, Inc.

East Tennessee Natural Gas Company

Egan Hub Partners, LP
Texas Eastern Transmission Corporation

Maritimes \& Northeast Pipeline LLC

Dynergy Midstream Pipeline, Inc.

- Venice Gathering System, LLC

ExxonMobil Pipeline Company

Foothills Pipe Lines Ltd

Gasunie, Netherlands

Great Lakes Gas Transmission Company

Iroquois Gas Transmission System, LP

Keyspan Energy

Nisource

- Columbia Gas Transmission Corp. Co.

- Columbia Gulf Transmission Co.

- Crossroads Pipeline Company

- Granite State Gas Transmission, Inc.

Oncor Group

- Oncor Gas

- TXU Gas/TXU Lone Star Pipeline

Ozark Gas Transmission System

Pacific Gas and Electric Gas TransmissionNorthwest Corporation

Sempra Energy Utilities/Southern California Gas Company

Southwest Gas Corporation

TransGas 
In the following sections, the survey responses are summarized in categories that correspond to the sections and questions asked in the survey itself. The questions are repeated (and presented in bold type to distinguish them) within each section to avoid the need to continually refer to Appendix A. In most instances, the data collected is presented in the form of a bar chart for easy interpretation.

Most respondents answered all the survey questions, but this was not always the case. As such, in many cases there were twenty responses to a particular question, in others there were less, and in some cases, such as the types of coatings used on pipelines, there were many more, since most companies have used several coating types over the years.

\section{Survey Responses}

\section{Part 1 - Currently-Used Repair Methods}

1. Describe the corrective actions your company has taken due to degradation (corrosion, cracking, etc.) of transmission pipelines, especially repair or replacement actions.

Figure 1 summarizes the responses received. The most common type of repair is a welded external steel sleeve which was mentioned fourteen times, followed closely by "cut-out and replace" which was listed thirteen times. ClockSpring®, grind-out repairs, and composite wraps were all mentioned eight times.

One response summarized the company's perspective in the following fashion: cut-out and replace cylinder (seldom), full encirclement steel sleeves (most common), direct deposition of weld metal (seldom, but frequency may increase), grinding to remove gouges (common), and welding a plugged fitting like a Threadolet over the damage.

After the degradation is detected by whatever means, repair protocols are used. For general corrosion these include steel sleeves or composite sleeves. For stress corrosion cracking (SCC), gouges, and sharp corrosion profiles, grinding is often used. Typically gouges are ground until the cold worked material has been removed and are sleeved where necessary. For cracks, much of the time these are cut out, however, there are times that cracks are ground out using in-house protocols. Repair of dents is carried out with steel reinforcement sleeves. All respondents indicated that excavations and repairs involve the replacement of the existing coating with liquid applied epoxy coating. 
One reply indicated that the first step was evaluation to ASME B31G. For repairs needed in lines that can be taken out of service, the solution is to either replace the damaged section as a "cylinder" or attach a sleeve. In the past, sleeves were exclusively steel, as technology has evolved, fiberglass wraps have been used. For low pressure lines leak clamps are used where appropriate.

In the case of internal corrosion, on-stream cleaning, chemical treatment, in-situ coating and in-situ polyethylene (PE) sleeve repairs have been applied. Recently, an internal repair approach of a $914 \mathrm{~m} \mathrm{(3,000} \mathrm{ft.)} \mathrm{long,} 607 \mathrm{~mm}$ (24 in.) diameter, river crossing was considered (http://www.unisert.com) using an internal fiberglass sleeve supported by a grouted annulus. Ultimately, a new HDD river crossing option was selected because of loss of cover in the river bottom.

Another respondent stated that a variety of repair methods are used, with the selection of the method dependent on several factors including class location, type of damage, operating pressure, and operational considerations.

Corrosion is repairable by a variety of repair methods dependent upon the conditions. Options include band clamp, mechanical sleeve, weld-on sleeve, ClockSpring ${ }^{\circledR}$, and replacement. External repair methods used by one company include sleeves (reinforcing, pressure containment), grinding (cracks) and pipe replacement. Another company indicated that they normally use ClockSpring $₫$ to re-enforce external corrosion areas, whereas cracks that exceed code limitations require an automatic cut-out (which is the last option to consider). Yet another company uses external repair techniques that include a simple blast and recoat, grind and recoat, ClockSpring ${ }^{\circledR}$ repair, welded sleeve repair or pipe replacement.

\section{Have you used methods other than external sleeving or pipe replacement to repair different types of degradation?}

The responses to this question were split 50\% "no" and 50\% "yes." The "yes" responses typically gave examples which are summarized as follows:

- Grinding is used to remove gouges (common), cracks, SCC, and sharp anomalies.

- Plugs are fitted and welded over the damage, e.g. a Threadolet.

- Composite wraps are used.

- ClockSpring® is used.

- Direct deposition welding has been used to repair wall loss 
- "Encapsulating" a malfunctioning or defective area has been used.

- Taps have been used for small defects.

- Leak clamps have also been used.

Seven of the responses mentioned grinding of one type of defect or another and was the most common other type of repair. Three examples of different types of welding solution were cited, of which only one involved direct deposition of weld metal on the outside of the pipe.

\section{What criteria (including ease of pipe access) affect choice of the specific repair method to be used?}

The compiled answers to this question are represented in Figure 2 and show twelve responses, of which cost and the availability of the repair method were those most frequently cited. The next important consideration is the position of the defect, and whether the line had to be out-of-service as the next most frequently mentioned criteria.

One respondent summarized the evaluated criteria as follows:

- Consequence of failure

- Position of defect (on bend, weld, top/bottom, etc.)

- Impact of a pressure restriction

- Cost of repair

- Type of defect

- Availability of repair method, crews, expertise, etc.

Another response listed the following criteria:

- Maximum allowable operating pressure (MAOP) and possible future increases

- Maximum operating pressure (MOP) at time of repair

- Pipeline specified minimum yield strength (SMYS)

- Downstream demand

- Ability to remove the pipeline from service

- Cost

- Projected life of the pipeline 
The size of flaw (surface area), the ability to shut in and replace the damaged section, the ratio of estimated failure pressure to MAOP, and the ability to stop additional degradation (in the case of internal corrosion) were stated as important criteria by another respondent.

Other responses follow:

- Must make repairs without taking the line out of service since it is not looped.

- Need to have the line out-of-service or at less pressure during repair work

- Can the pipeline be taken out-of-service, gas loss?

- Leak history

- Corrosion records

- ILI (in-line inspection) logs

- Cost (access, out-of-service time, mobilization time, etc.)

- Reliability (how reliable is the repair method to fix the problem, permanent repair, temp. repair)

- Safety issues

- Operator qualification

- $\quad$ Type and depth

- Material properties and type of pipes, e.g. electric resistance welded (ERW), seamless, etc.

- Coating

- Location (proximity to housing or public facilities)

- Operational timing (ability to take line out-of-service, i.e. impacts to customers and system)

- Type or severity of defect, access to site, time constraints in regards to length of line outage or restriction, soil conditions (e.g. swamp, rock, etc.), environmental issues (wetlands, streams, etc.).

- Pressure, Department of Transportation (DOT) status (we operate many rural gathering lines), contents of line, risk to public

- Location, pipe condition, operating pressure/SMYS, pipe geometry (e.g. straight, over-bend, sag, etc.) 


\section{Comments pertaining to currently used repair methods.}

Not unexpectedly, comments ranged from:

- Most of our line has easy access

- The use of sleeves for the repair of external flaws has been satisfactory to date

- Most existing methods have been effective

- The ClockSpring® has been a very useful repair method in the last few years

- Many are very difficult in swamp or underwater locations

Cut-out repair is considered the last resort due to flow disruption and overall cost.

External faults are more readily repaired using sleeves than internal anomalies. Internal damage requiring repair in bends equate to a pipe replacement. The threshold for pipe replacement versus repair decreases once the first replacement in a section is justified.

Live repair methods require a reduction in operating pressure. Normally the excavation trench requires tight sheeting and shoring, a certified welder, and qualified maintenance welding procedure with low hydrogen procedures (e.g. E7018 low hydrogen electrodes).

\section{Part 2 - Use/Potential Use of Internal Repair}

\section{Has your company attempted repair of a transmission line from inside the pipe?}

Of the nineteen responses to this question, only one was "yes." Another company indicated that they considered the use of the Pacific Gas \& Electric (PG\&E) tool for weld repair on the internal diameter, but the expense was said to be large and the diameter range was limited. Other companies raised the question of how to ensure the quality of the repair.

\section{If so, describe the repair(s)}

Plastic tight liners were used and for lower pressure lines (less than 100 psig MAOP) slip lined plastic liners have been used. Both of these methods require the line to be out of service when repair is made. 


\section{There are many factors that affect the decision to repair or replace pipe. What circumstances would favor performing a repair from inside the pipe using only one or two excavations rather than excavating the entire length of pipe?}

Figure 3 shows the primary factor for choice of an internal repair method is road and river crossings. Confidence in repair method, presence of numerous but localized areas of damage, inability to excavate large areas because of environmental permitting issues, economics/cost and availability of a proven, industry (and regulator) accepted internal method were also factors mentioned.

Specific comments follow:

- Depending on the depth of burial and the presence of over-bends, sag bends or side-bends or road/river crossings etc., then an internal repair may be much more preferable than cutting out the piece of affected pipe. Single barrel pipelines (versus looped lines) are more difficult to remove from service (customer interruption).

- Factors, such as, class location, environmentally sensitive areas, in crossings, under waterways or rugged terrain would be some of the major factors influencing this decision; an anomaly found inside a casing might be (a factor), under a road, irrigation canal, or railroad tracks; difficult to excavate locations (e.g. rocky conditions, caliche soils, etc.); and cost would be another factor influencing the decision. This potential technology would also be useful for locating and repairing internal wall loss identified by ILI inspections without excavation of the entire pipeline and numerous cuts to the line.

- Property damages, contractor costs, inaccessible right-of-way, lack of temporary workspace, road, railroad, and stream crossings sometimes must be replaced just because indicated damage cannot be directly measured highway crossings, railroad crossings, and heavy traffic intersections.

- Highly congested areas that impact risk to other pipelines or utilities and proximity to structures.

- Possibly a pipeline under water or a permanent structure where the pipeline is not easily accessible

- Where the pipe repair is located under a road or body of water where access is limited.

- Pipelines that are under paved areas, or in narrow or confined rights-of-way where space is limited. Crossings at roads, railroads, lakes, and rivers, and water cover, such as, marsh or swamp. 
- If the cost of an internal repair plus the outage restriction was less than the cost of an external repair. For example, if the defect was in the middle of a major water crossing or swamp which would normally require ice road construction for access.

- $\quad$ High traffic areas

- Federal, state, city or c ounty roadway restoration requirements

- Environmental concerns

- Railway crossings

\section{If the technology were available to perform a repair from the inside, would your company consider using the technology?}

One "no" response was received. The other seventeen responses were "yes" and some were qualified with additional comments as follows:

- We would want to review testing and possibly witness a demonstration

- Only if proven

- If cost is reasonable

- Particularly if DOT compatible

- Depending on the site-specific conditions

One response indicated that the company transports non-corrosive natural gas, so the probability of an internal flaw is highly unlikely. While this may be true for many companies in terms of internal corrosion, it misses the point that the internal repair can be used for repair of external damage.

\section{If so, for what application(s) - e.g., specific geographic locations and special situations?}

Figure 4 summarizes the answers to this question. River crossings and populated areas with highway crossings were most frequently cited. Use for repair of flaws found by pigging, included internal or external corrosion pitting, gouges, seam or weld flaws (if detectable by pigging).

Seven responses mentioned river crossings and this was the most common response to this question. Others cited pipelines that are under paved areas, or in narrow or confined rights-of-way where space is limited, crossings at roads, railroads, lakes, swamp areas, and difficult access due to physical barriers inherent to high population density and congested areas (e.g., numerous utilities, building, streets, etc.). 
One response mentioned concerns regarding the use of internal repair on a direction bored crossing of a freeway, because of unknown future cathodic protection (CP) effectiveness after welding.

Another response referred to applications where it is not cost effective to repair or replace the pipe conventionally, provided the internal repair is an equivalent repair. Probably the best application in this case would be offshore.

\section{At least one excavation will be required to insert the internal repair device into the} pipe. From this excavation, the repair device could travel in each direction from the excavation. About how far from the insertion point should the repair device be able to travel?

Answers ranged from $15 \mathrm{~m}$ (50 ft.) to $113 \mathrm{~km}$ (70 miles); the latter for offshore operation, with most answers being in the $305 \mathrm{~m}$ to $915 \mathrm{~m}(1,000 \mathrm{ft}$. to 3,000 ft.) range. The array of responses is summarized in Figure 5, showing that there are discrete lengths of $305 \mathrm{~m}$

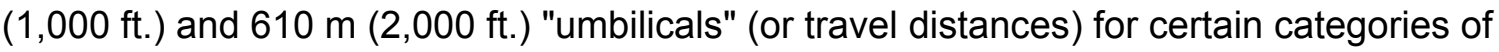
repairs or related requirements. The typical travel distances required are divided into three groups; up to $305 \mathrm{~m}$ (1,000 ft.); between $305 \mathrm{~m}$ to $610 \mathrm{~m}$ (1,000 ft. and 2,000 ft.); and

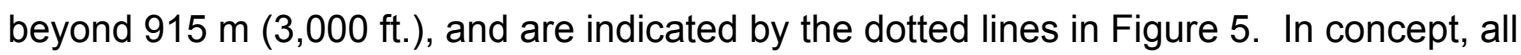
these systems would be pig-based. Systems with despooled umbilicals could be considered for the first two groups, while the last group would be better served with a self propelled system with self-contained onboard power and welding system.

$152 \mathrm{~m}$ (500 ft.) appears to be adequate to cross most interstate highway crossings and 610 $\mathrm{m}(2,000 \mathrm{ft}$.) for all river crossings. A major river crossing would require the device to travel up to $610 \mathrm{~m}(2,000 \mathrm{ft}$.). In one case it was stated that the longest section of pipe which is not accessible (directional bore) is approximately $1,219 \mathrm{~m}(4,000 \mathrm{ft}$.$) , so the need would be$ to access the pipe a distance of approximately $610 \mathrm{~m}(2,000 \mathrm{ft}$.) from either end.

Longer distances, probably from $915 \mathrm{~m}$ (3,000 ft.) to several miles or more would require the technology to travel in a similar way as an inspection pig. Realistically, such a system would have to be based on an onboard propulsion device using gas line pressure as the motive force. A self-contained, inverter-based welding power source and welding system would also be required.

\section{In what range of pipe diameters should the repair device be capable of operation?}

A wide range of pipe sizes were cited, both within a particular company, and between various companies. The results are summarized in Figure 6 show that pipe size range 
requirements run from $51 \mathrm{~mm}$ ( 2 in.) through $1,219 \mathrm{~mm}$ (48 in.) diameter. The common size range for $80 \%$ to $90 \%$ of operators surveyed is $508 \mathrm{~mm}$ to $762 \mathrm{~mm}$ (20 in. to $30 \mathrm{in}$.) diameter, with $95 \%$ using $559 \mathrm{~mm}$ (22 in.) diameter pipe.

\section{What potential obstructions such as elbows, bends, branches, and taps should the repair system be able to negotiate?}

The answers to this question were quite varied and are summarized in Figure 7. Pipe bends of various radii were most commonly mentioned including 1.5 times the diameter (1.5D), 3 times the diameter (3D), and 6 times the diameter (6D), with 3D pipe bends being the most commonly used. Elbows were mentioned in three responses. It is interesting to note that the answer "all" was given four times.

\section{For the situations described in Question \#3, at what approximate cost would an internal repair method become competitive with existing repair options?}

Statements and cost figures varied widely from $\$ 25,000$ to $\$ 1,000,000$ depending on the perspective of the survey respondent and the terrain that their pipeline systems crossed (see Figure 8).

One reply indicated that internal repair probably would not be competitive with external repair/replacement except in river crossings. Anything cheaper than a new HDD and tie-in would be economical in that case.

One company indicated that the cost is related directly to the amount of time the pipeline would be out of service. For major river/road crossings the technology would be competing with HDD @ $\$ 1,000 / 305 \mathrm{~m}(\$ 1,000 / \mathrm{ft}$.). On land, if one can dig up the area and cut out the affected piece of pipe faster than repairing it, then this is what companies would do since the cost of the pipe and a couple of field welds is inconsequential compared with the cost of having the pipeline out of service. The potential cost option could be the reconstruction of a river crossing or other directionally bored crossing.

One respondent indicated that pipe repairs without external access are typically expensive, thus limiting the types of repairs to critical service lines. Repair costs, if the repair can be quickly mobilized (i.e. leaking system) and be confidently applied, can approach $\$ 1,000,000$. Therefore the repair would have to serve as a permanent repair.

Another company noted that existing external methods are relatively inexpensive. Repairs required in an area that is inaccessible to current external repair methods can be very expensive and vary by the pipe size, length, and situation. The advantage will be to repair multiple locations or hard to reach locations with minimal excavation. Quite reasonably, 
several respondents answered that this would have to be examined on a case-by-case basis.

Yet another response indicated that an internal repair tool would be valuable where the pipe is inaccessible. Replacing a road crossing/directional bore could range from $\$ 50,000$ to $\$ 1,000,000$ depending on the size of pipe/distance. Other quantitative replies were within the wide range of about $\$ 30,000$ to $\$ 60,000$ per repair site in one case; for repairs other than in crossings, about $\$ 25,000$ per site total including excavation, recoating and backfill; and another reply mentioned about $\$ 200,000$, while a another response indicated that an internal repair would have to be $50 \%$ to $75 \%$ of the cost for a conventional repair/replacement to be competitive.

7. Have new regulatory requirements created a need to improve the fitness for service of existing transmission lines via localized repair or removal of conditions that are acceptable under previous criteria?

Responses to this question were varied, with six "no" responses and nine "yes" responses. Specific remarks are listed below:

- Not in Canada - new requirements only change documentation effort.

- Regulations will require companies to prove the fitness for purpose of their pipelines rather than improve. There maybe circumstances with HCA's where repairs are now required.

- Some, but I see this as having little impact on the use of this technology. The newly proposed pipeline integrity regulation will make us more aware more quickly to the extent of repair required.

- Under the current Texas Railroad Commission Integrity Rule, and the pending DOT integrity rule, operators are in-line inspecting more pipe than has been done in the past. More repairs may be necessary as a result of more inspections.

- Upcoming inspection requirements may result in the discovery of defects requiring repairs that would not otherwise have been discovered. Increased cost of excavation restoration has been imposed by various municipalities.

8. What is the estimated number of repairs per year which could potentially be performed by internal repair in your company for the reasons discussed in Questions \#3 and \#7?

Responses varied from "none," through "1 repair in 5 years," and in one case "10-75 repairs per site." These answers are summarized in Figure 9 which shows that answers 
from " 1 repair in 5 years," up to " 5 repairs per year" were by far the most common response. This indicates a limited expected requirement for such a system, particularly based on expected relative cost to purchase and operate. This supports the suggestion that pigging operators would be the best source to supply and operate such equipment on a contracted basis.

\section{Comments pertaining to the use/potential use of internal repair.}

Significant individual responses follow:

- Internal methods would be hard to accept as it would be difficult for QA/QC and direct inspection.

- It would have to provide a permanent repair and be piggable to be worthwhile.

- Reinforcing weld joints internally for the in-service pipelines built using welding process, which produced joints with incomplete penetration and lack of fusions.

- Any internal repair sites would have to still be capable of passing an ILI tool and be visible to that tool.

- Internal repair could not impede the ability to pig lines and still be a viable option.

- The major concern would be not to obstruct subsequent ability to assess the pipeline's integrity through internal inspection schemes.

- It is a good to have, whenever necessary.

- A method of inspection of the repaired area may need to be devised.

- It would seem that internal repair methods would have minimal use unless long distances need repaired in congested locations.

- Offshore or underwater (e.g. river crossings, swamps, etc.) offer best economics.

- It would be a valuable tool to have; however, I see no advantage to the process for pipe which is accessible. The only value would be where pipe is inaccessible in a $\mathrm{road} / \mathrm{stream}$.

- The use of an internal repair would probably be driven by the discovery of unacceptable corrosion in an inaccessible location. We are currently unaware of this situation in our system.

Part 3 - Need for In-Service Internal Repair 


\section{How important is the ability to perform a repair from the inside the pipe while the pipeline remains in service?}

The majority of survey respondents considered the ability for the pipeline to remain in service while the repair was conducted to be very important (Figure 10), especially if their system was not looped. Companies with looped pipeline systems presumably account for the respondents that considered this to be only somewhat important.

Significant individual responses:

- If the pipeline could remain in service the probability of using the tool would be very greatly increased.

- The ability to keep a pipeline in service during repair work would be an important factor when considering internal repair as a possible option.

- Very important for the economics of a large diameter transmission line. Keeping the line in-service is a distinct advantage over cut-out.

- $\quad$ For us it would be important because we are not looped.

- Because this may compete with external sleeving, I think that this is real important.

- This repair method would save gas that would normally be lost and would allow service to be uninterrupted. It is very important.

- Minimizing business disruptions to key customers is important. This ability would make such a repair method very important.

- For those pipelines where service cannot be interrupted and where welding is impractical, it is very important. 


\section{Would internal repair remain attractive if it was necessary to completely shut down the pipeline (depressurized and evacuated) during the repair?}

The answers summarized in Figure 11 include six "yes" and three "no," with a variety of other responses in between.

Twelve respondents collectively indicated that this depends on a number of other criteria. It would remain attractive if:

- It could eliminate the need to build an ice road in the swamp or dam and flume a river

- in highly congested areas it could be attractive

- Could be where it is too hard to get to the defect location directly like under a river, lake, for offshore and underwater.

- For offshore environments, shut-in is possible, blow-down probably an extra $\$ 100 \mathrm{k}$ minimum dependant upon gas prices.

- To depressurize and evacuate the gas adds cost that would affect how attractive this type of repair would be.

\section{Depressurized but not evacuated?}

Responses are presented in Figure 12: there were eight "yes" responses and two "no" responses.

Individual responses:

- Depressurized but still flowing is better.

- Depressurized and not flowing is poor; usually the cost of excavation is minor compared to the outage.

- It is typically not possible to depressurize without a blow down and would not be as attractive.

- There could still possibly be applications but would then be much more a function of the cost of the internal repair versus the cost of external repair or replacement. 


\section{Out-of-service (no flow), but remain pressurized?}

Responses are summarized in Figure 13: there were eleven "yes" responses and two "no" responses. If the pipeline must be out-of-service, the amount of pressure remaining and whether or not it is evacuated are probably far lesser considerations.

Specific responses:

- This is more attractive than the previous two.

- It would be an attractive repair technology under these conditions.

- Leaving the line pressurized would reduce the gas lost, and reduce the potential cost of the repair.

\section{Comments pertaining to the need for in-service internal repair.}

One response commented that hopefully internal repair would only be required for operators who transport wet or corrosive products. This comment refers to their lack of internal corrosion damage, but also indicates a lack of understanding that the internal repair could be used to repair external corrosion damage. An internal repair appears to be attractive if it reduces the potential for gas lost from blowing down a pipeline, and reduces cost, and/or reduces out-of-service time. Obviously, as the price of gas increases each of the above options will have more impact.

\section{Part 4 - Applicable Types of Damage}

1. What types of external coatings would be found on transmission lines owned by your company?

A wide variety of coatings were cited ranging from none (bare steel pipe) through a wide range of bitumastic, coal tar, wax; plastic and composite tapes and wraps; to POWERCRETE $®$ and concrete. The number of responses indicating the use of each coating type is summarized in Figure 14. The top three coating types mentioned were fusion bonded epoxy (FBE), coal tar, and concrete/POWERCRETE®. 


\section{If a repair involving welding from the inside was performed, how important is it to preserve the integrity of the coating?}

The ten responses are summarized in Figure 15. There were ten responses to this question. One company indicated a level of importance of "important," six companies listed the level as "very important," and three indicated a level of "critical/essential." Five respondents commented that preserving the coating integrity was not very important, as the CP system was considered capable of taking care of local degradation in these instances.

Individual responses:

- It is of utmost importance.

- If the existing coating cannot be maintained, then additional excavations will be necessary and the coating repaired.

- It is very important for large damaged areas since access to site to repair the coating may be difficult.

- It is necessary to try to preserve as much coating as possible since the repair may be applied to an area of external corrosion and we would not be able to assess the root cause of the corrosion or know if it is mitigated.

- An offshore pipeline operator suggested that perhaps considering attaching an anode if necessary, but then again, reasonable access would be required. In offshore applications, a small amount of coating damage is not too much of a problem.

\section{Is your cathodic protection system capable of compensating for relatively small breaches in the coating?}

The results here are shown in Figure 16. All respondents said that the CP system is capable of compensating for relatively small breaches in the coating: there were thirteen "yes" responses and five qualified "yes" responses.

Comments received:

- Preservation of external coating must be a major consideration.

- Not for disbonded coating.

- It would not meet DOT code requirements under 192/195.

- We do not want any breaches or holidays in their coatings. Coating damage would reduce the attractiveness of this repair system. 
One company stated that the CP system can normally compensate, but that one would have to consider that if you had an external corrosion anomaly at the repair site, you may repair it and still have an active external corrosion site. The internal repair would have to be fully pressure containing. Also, if the weld damages good coating, and there is some localized issues with CP protection, that may set-up an active corrosion site at the weld sites (especially if damaged coating is left disbonded and shielded from CP).

\section{Comments pertaining to applicable types of damage.}

The following three comments were received:

- I would not want to trade a known likelihood of external coating damage in order to permit an internal repair.

- I do not think the industry or the regulators would accept a repair method that damages the coating and leaves it in worse shape than originally found

- If the coating is damaged and CP shielding occurs, then problems would be great. It may be possible to install a Magnesium (Mg) anode at the repair location to spot protect damage to the coating.

\section{Part 5 - Operational and Performance Requirements for Internal Repairs}

1. Two general categories of repairs are being considered, (1) using weld metal to restore a surface and (2) installing an internal sleeve, either metallic or nonmetallic, to provide structural reinforcement of leak tightness. Is it important that the line remain inspectable by pigging after repair?

The responses are summarized in Figure 17, which shows the unanimous response was "yes."

The five "yes" responses contained the following comments:

- Maybe not for a temporary repair. One scenario that comes to mind is in the mountains where there is too much snow to access. A temporary repair could be made and not worry about ILI restriction. Would perform cut-out in the summer.

- Yes, if original line was piggable.

- $\quad$ DOT code 49 CFR 192.150 states that all new lines, or line repaired, will be able to accommodate the passage of an ILI device. Additionally, with the new integrity 
management rules requiring regular pigging of pipelines, any internal repair would have to allow the passage of a pig.

- Under existing DOT codes it would seem that being able to inspect the line is required. New pipeline integrity regulations may allow for alternative methods.

- For some lines, being "smart- piggable" after repair would be mandatory.

\section{About how far could the repair protrude into the pipe before it would interfere with pigging?}

The responses are summarized in Figure 18. Six responses gave a range in the region of $5 \%$ to $10 \%$ of nominal pipe diameter. Even for relatively small diameter pipe this amount of protrusion could be quite large.

Seeking guidance from pigging vendors was suggested by seven of the responses. An amount of $1 \%$ of diameter was considered a good number as a rule of thumb in one case. In another, about $1.5 \mathrm{~mm}$ (0.6 in.) for a $914 \mathrm{~mm}$ (36 in.) pipe (2\% of diameter) was mentioned. Several responses mentioned that the type of pig is an important consideration when considering an answer to this question. A "smart pig" was said to be able to accommodate a $10 \%$ reduction in diameter.

One response stated that the acceptable protrusion varies depending on the type of pig, pipe size, geometry, and longitudinal length of the restriction. Another response stated that this is dependent upon the type of pigging utilized (e.g., traditional versus smart).

\section{What NDE would your utility require for a repair to an existing longitudinal or circumferential weld?}

Thirteen survey respondents included radiographic testing (RT) or indicated that only radiographic inspection was used or allowed; five indicated that ultrasonic testing (UT) is also permitted; and two responses indicated that magnetic particle inspection (MPI) is also allowed (see Figure 19).

UT or RT acceptability is judged to code acceptance criteria; specifically ASME B31.8 or B31.4, and CSA Z662 codes were mentioned. In one case it was noted that all welds below $40 \%$ SMYS are repaired with a reinforcement sleeve/canopy or removed from the system. In another, it was stated that inspection must comply with Part 192 NDE requirements. 
What NDE would your utility require for a welded repair to base metal (e.g. corrosion pitting)?

Figure 20 summarizes the NDE requirements for weld repair to base metal: seven responses include or only use/allow $R T$, three responses include UT as an acceptable alternative to RT, and three responses include MPI. UT or RT acceptability to code acceptance criteria ASME B31.8 or ASME B31.4 were also mentioned. In one case, it was noted that, at a minimum, all weld repairs are visually inspected and soap tested. Another response indicated that all welds must meet the acceptability standards of the currently referenced edition of the API 1104.

\section{Could a visual or magnetic particle examination be substituted for radiography in these special circumstances?}

The answers to the question were evenly distributed. There were three "yes" only responses, three qualified "yes" answers, three "MPI not visual," three "maybe," three "no," and three "don't know."

Specific comments:

- On fillet welds to the base metal, yes. For the long seam repair, probably not.

- Below 40\% SMYS repairs utilizing pre-qualified components with a manufacturer established MAOP require both a visual and a soap test.

- I am not sure how the MPI would be done remotely, but it would have value.

\section{Would the use of internal repair be attractive even if it were considered a temporary repair?}

The answers to this question were mixed, as summarized in Figure 21: eight were "no" responses, three were "yes" only, and eight were qualified "yes" responses.

Individual comments:

- In some circumstances, especially in seasonal climates (Canada, mountains, muskeg).

- Yes, if it could be done at relatively low cost (competing with an external sleeve, which is permanent) and with little to no interruption in service.

- Only if the cost was very low.

- If we were using this as a repair, we would rather have a permanent solution. 
- Only in a very limited number of cases.

- It could be to allow for scheduling repairs and avoid a shut down during critical times.

- Yes - if it could be accomplished without purging the pipeline.

- Possibly, dependent upon the situation.

\section{Comments pertaining to operational and performance requirements for internal repairs.}

Specific responses:

- Repairs would need to be as good as the original pipe; one wouldn't want to create local corrosion cells if the weld filler metal was more/less active than the base metal. This would only be attractive if shutdown is not required and no excavation is required to find the defect.

- The internal repair should provide for a smooth internal surface. The weld repair would not leave an area subject to long term cracking. CP would not be compromised. Repair will not interfere with future inspections.

\section{Part 6 - General Comments}

Please provide any general comments that you may have. For example, comments on an acceptable range of commercial pricing for such a system would be useful (as distinct from a repair cost in Question\#6 of Part 2).

Individual responses follow:

- This would not be a piece of equipment that our company would use often enough to justify us owning it. The most effective management of this system may be through a smart pigging company that could offer this as a follow-on service after inspection.

- The internal repair should return pipe to its original serviceability and safety factor. Pricing would determine selection if the repair was appropriate and proven for the type of defect. The costs are going to be weighed against the cost of excavation and the need to purge the line. Quite often, corrosion damage and even some dents can be repaired with steel sleeves using hot tap procedures so the pipeline does not have to be shut down. In swamp conditions, excavation is very expensive due to special equipment and the need to construct isolation dams to keep out the 
water and use pumps to dry the hole. Of course, offshore repairs require divers and habitats. The internal repair method would have the best economics for underwater repair locations. Some urban areas may have the same type of economics.

- Having an internal welding tool option would be very advantageous for a given situation. That situation is a totally inaccessible location such as a directional bore. For a busy intersection or street alignment where the pipeline can be accessed by conventional method at a high cost, accessing the pipeline externally would be preferred. The repair method would have to be approved by DOT prior to being used.

- The cost depends mainly on the requirements of the repair as in pipe size, length, customer outages, etc. I would say that it has to be considerably less then the standard repair methods to make the new repair method accepted by industry. Because it is internal and the integrity of the repair has to be assessed through some form of NDE, the actual repair strength will be hard to sell. 


\subsection{CONCLUSIONS}

The twenty survey responses produced the following principal conclusions:

1. Use of internal weld repair is most attractive for river crossings, under other bodies of water such as lakes and swamps, in difficult soil conditions, under highways and in congested intersections, and under railway crossings. All these areas tend to be very difficult and very costly, if, and where conventional excavated repairs may be currently used.

2. Internal pipe repair offers a strong potential advantage to the high cost of HDD when a new bore must be created to solve a leak or other problem in a water/river crossing.

3. The typical travel distances required can be divided into three groups: up to $305 \mathrm{~m}(1,000 \mathrm{ft}$.);

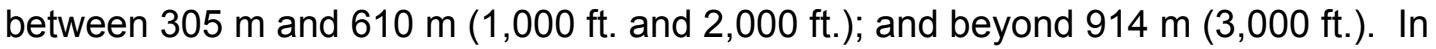
concept, all appropriate systems would be pig-based. Systems with despooled umbilicals could be considered for the first two groups, with a self propelled system with self-contained onboard power and welding system for the third.

4. Pipe size range requirements run from $50.8 \mathrm{~mm}$ (2 in.) through 1,219.2 $\mathrm{mm}$ (48 in.) in diameter. Of the survey respondents, a common size range for $80 \%$ to $90 \%$ of operators is $508 \mathrm{~mm}$ to $762 \mathrm{~mm}$ (20 in. to 30 in.) in diameter, with $95 \%$ using $558.8 \mathrm{~mm}$ (22 in.) diameter pipe.

5. Based on the frequency of expected use by many operators, the issue of acceptable system cost for a deployable solution could best be tackled through selling such technology as an additional service through existing "smart pig" vendors/operators.

6. There has been almost no use of internal repair to date and the concept is currently fairly alien to pipeline operators. Even the potential for internal repair of external damage using such a system needs further promotion/education within the industry as a whole.

7. Most operators were open to the economic potential an internal repair system may offer in terms of reducing interruption to product flow, particularly if they did not have looped lines.

8. The top three items of concern for selecting a repair method were cost, availability of the repair method (time/cost), and the position of the defect(s).

9. A wide range of pipe coatings were cited as being deployed in the field. The top three mentioned were FBE, coal tar, and concrete/POWERCRETE $®$.

10. The majority of operators considered the ability for the pipeline to remain in service while the repair was conducted to be very important.

11. RT is by far the most accepted method for pipeline NDE. UT was the second most common process cited. 


\subsection{REFERENCES}

Not applicable, as the contents of this report are based on direct contact with fifty-four companies who provided twenty responses to the survey.

\subsection{BIBLIOGRAPHY}

Not applicable, as the contents of this report are based on direct contact with fifty-four companies who provided twenty responses to the survey.

\subsection{LIST OF ACRONYMS}

$\begin{array}{ll}\text { Acronym } & \text { Definition } \\ \text { API } & \text { American Petroleum Institute } \\ \text { ASME } & \text { American Society of Mechanical Engineers } \\ \text { CP } & \text { Cathodic Protection } \\ \text { CSA } & \text { Canadian Standards Association } \\ \text { DOT } & \text { Department of Transportation } \\ \text { ERW } & \text { Electric Resistance Welded } \\ \text { FBE } & \text { Fusion Bonded Epoxy } \\ \text { HDD } & \text { Horizontal Direct Drilling } \\ \text { ILI } & \text { In-Line Inspection } \\ \text { MAOP } & \text { Maximum Allowable Operating Pressure } \\ \text { MOP } & \text { Maximum Operating Pressure } \\ \text { MPI } & \text { Magnetic Particle Inspection } \\ \text { NDE } & \text { Nondestructive Examination } \\ \text { PE } & \text { Polyethylene } \\ \text { PG\&E } & \text { Pacific Gas \& Electric Co. } \\ \text { PRCI } & \text { Pipeline Research Council International } \\ \text { QA } & \text { Quality Assurance } \\ \text { QC } & \text { Quality Control } \\ \text { RT } & \text { Radiographic Testing } \\ \text { SCC } & \text { Stress Corrosion Cracking } \\ \text { SMYS } & \text { Specified Minimum Yield Strength } \\ \text { UT } & \text { Ultrasonic Testing } \\ & \end{array}$


Figure 1 - Currently Used Repair Methods

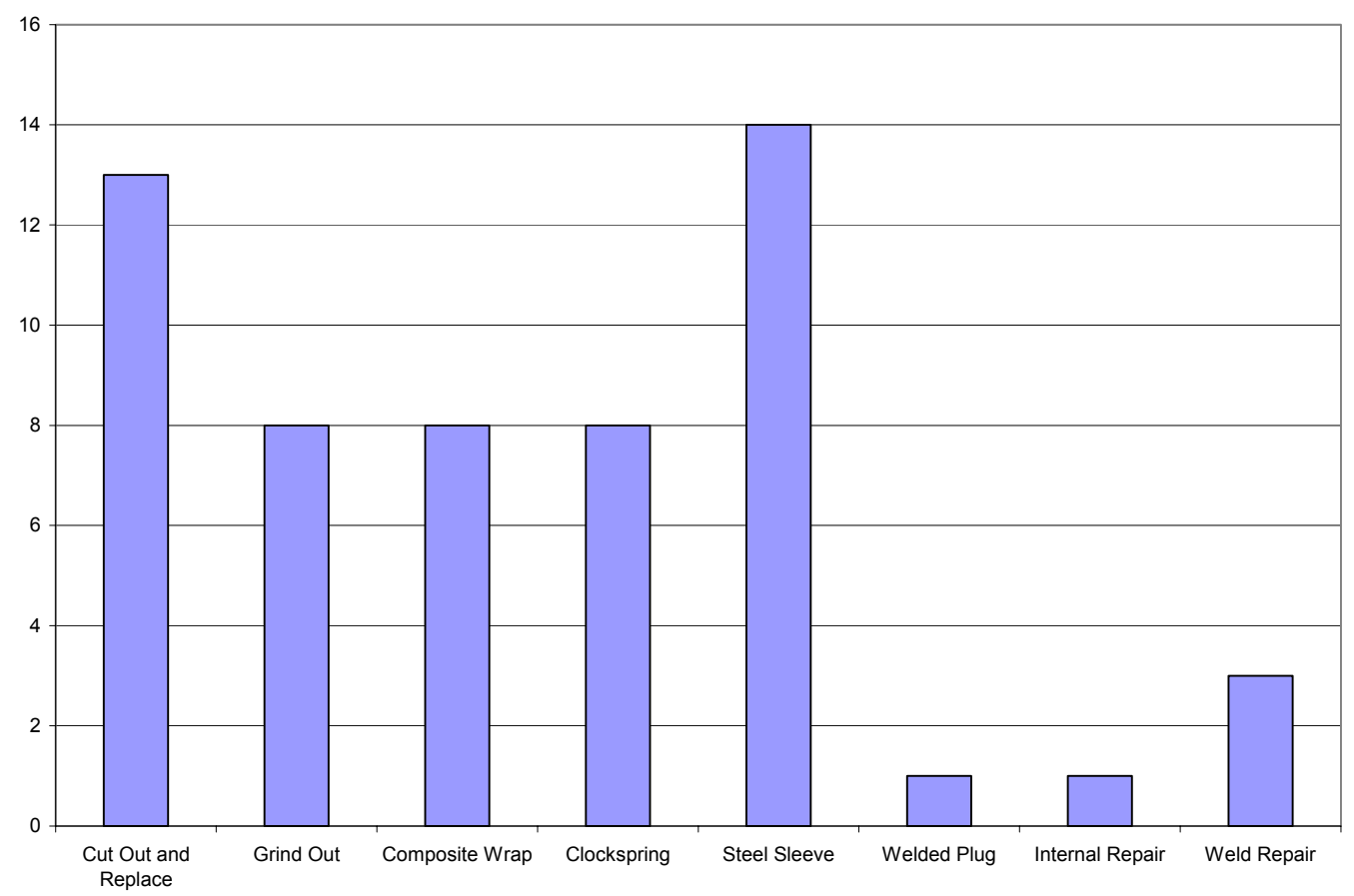

Figure 2 - Criteria Affecting Choice of Repair Method

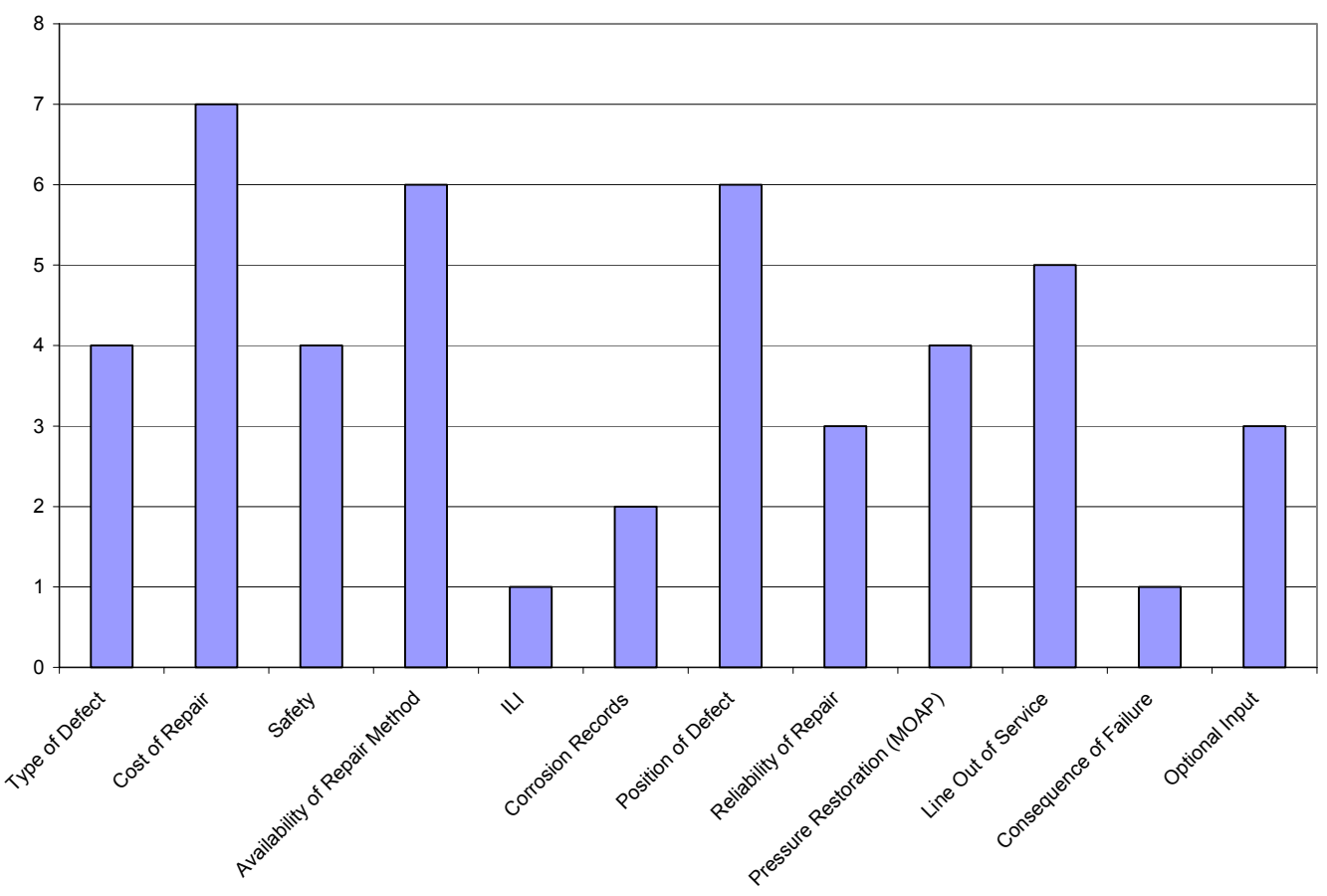


Figure 3 - Decision Factions for Internal Pipe Repair

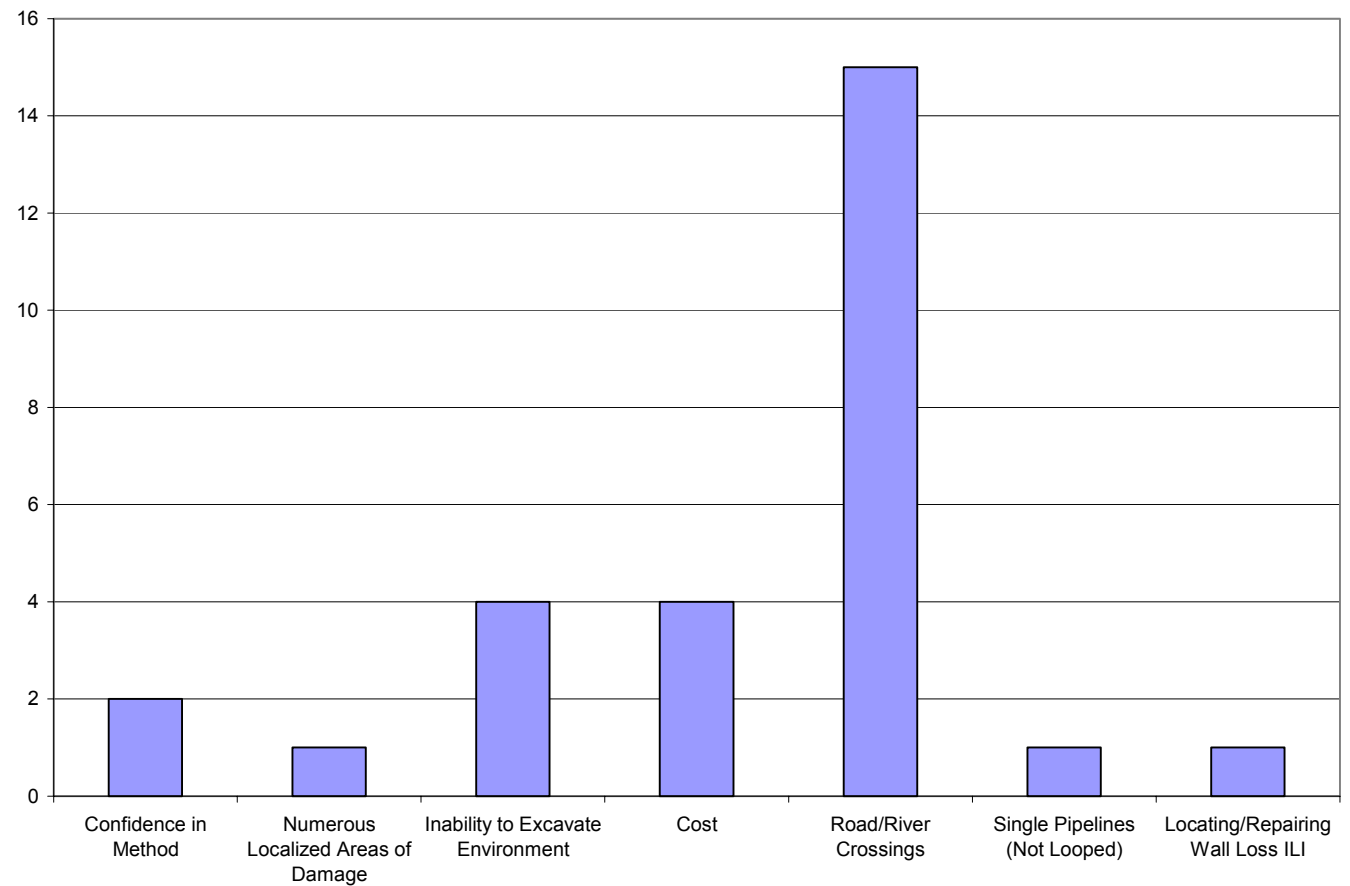

Figure 4 - Specific Geographic Locations and Special Situations

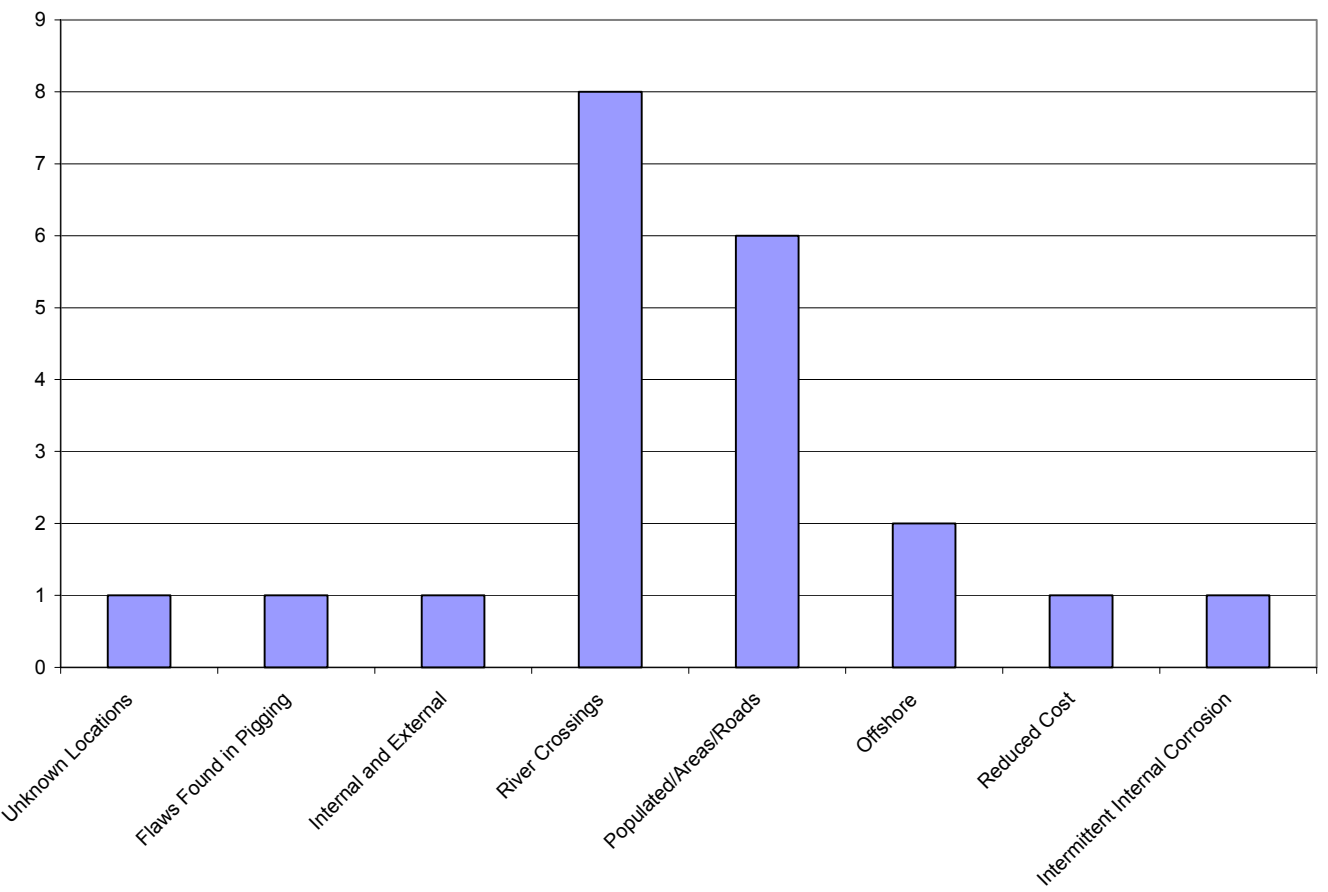


Figure 5 - Distance Repair System Required to Travel Down Pipe

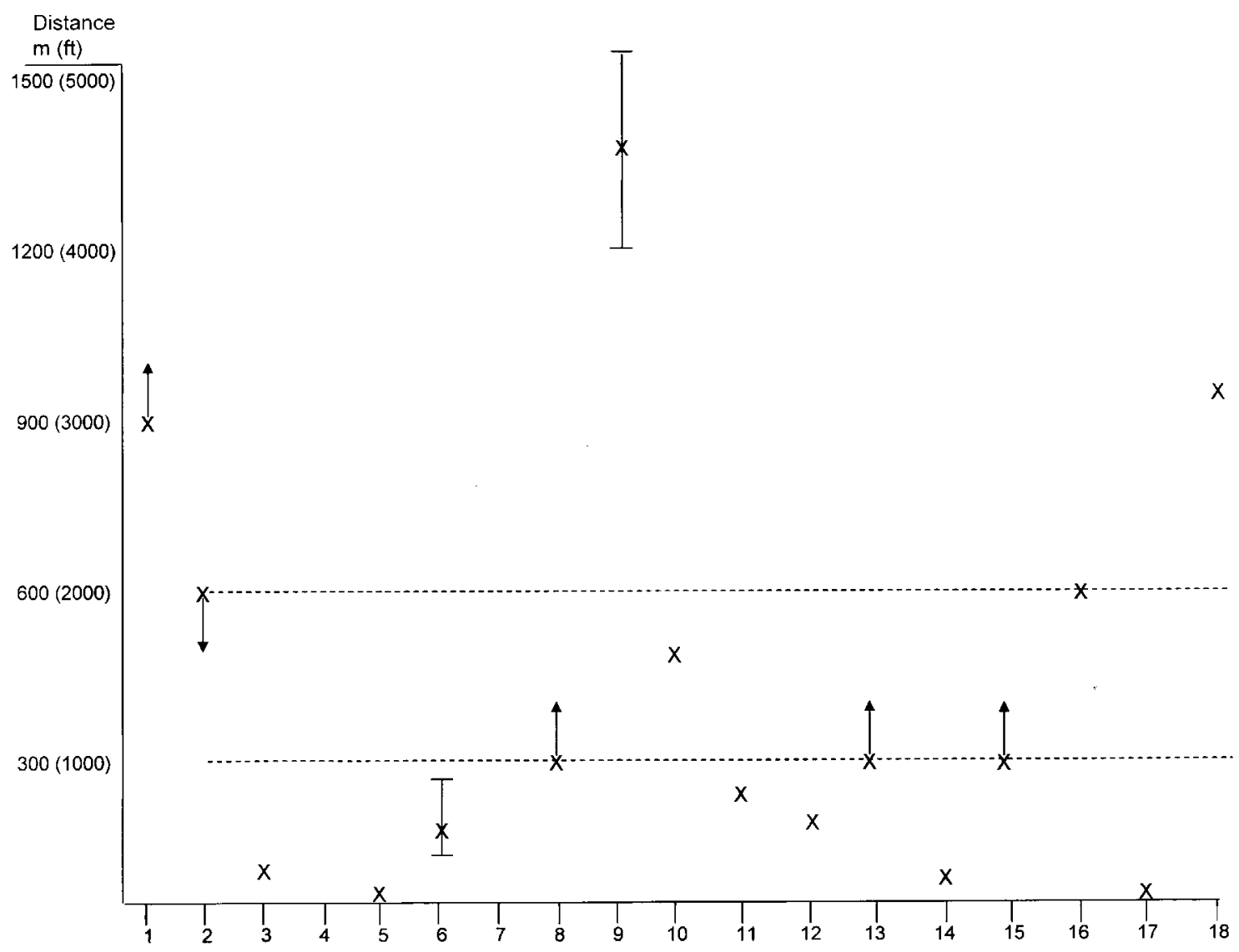


Figure 6 - Range of Pipe Diameters Used

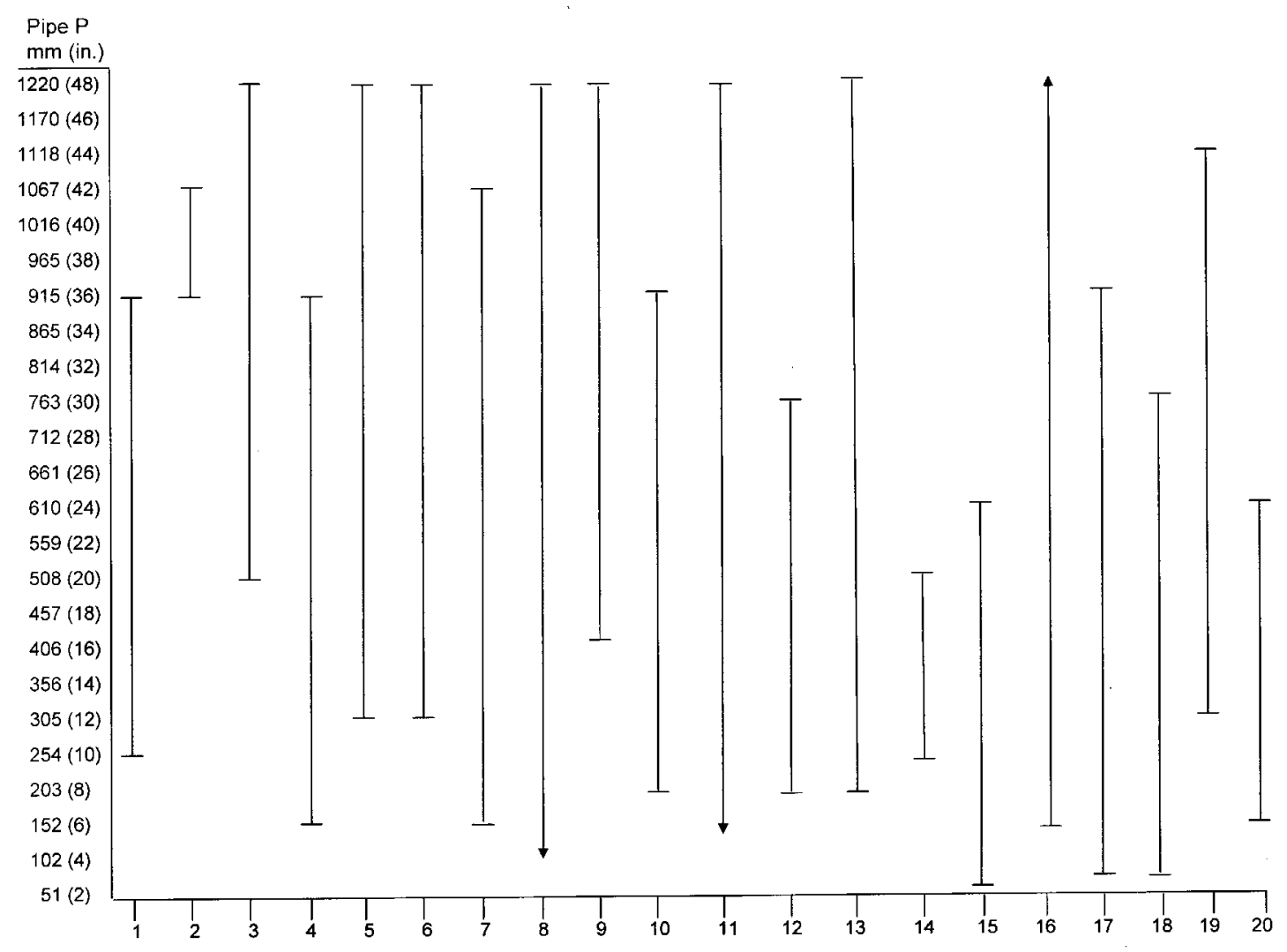


Figure 7 - Potential Obstructions to be Negotiated

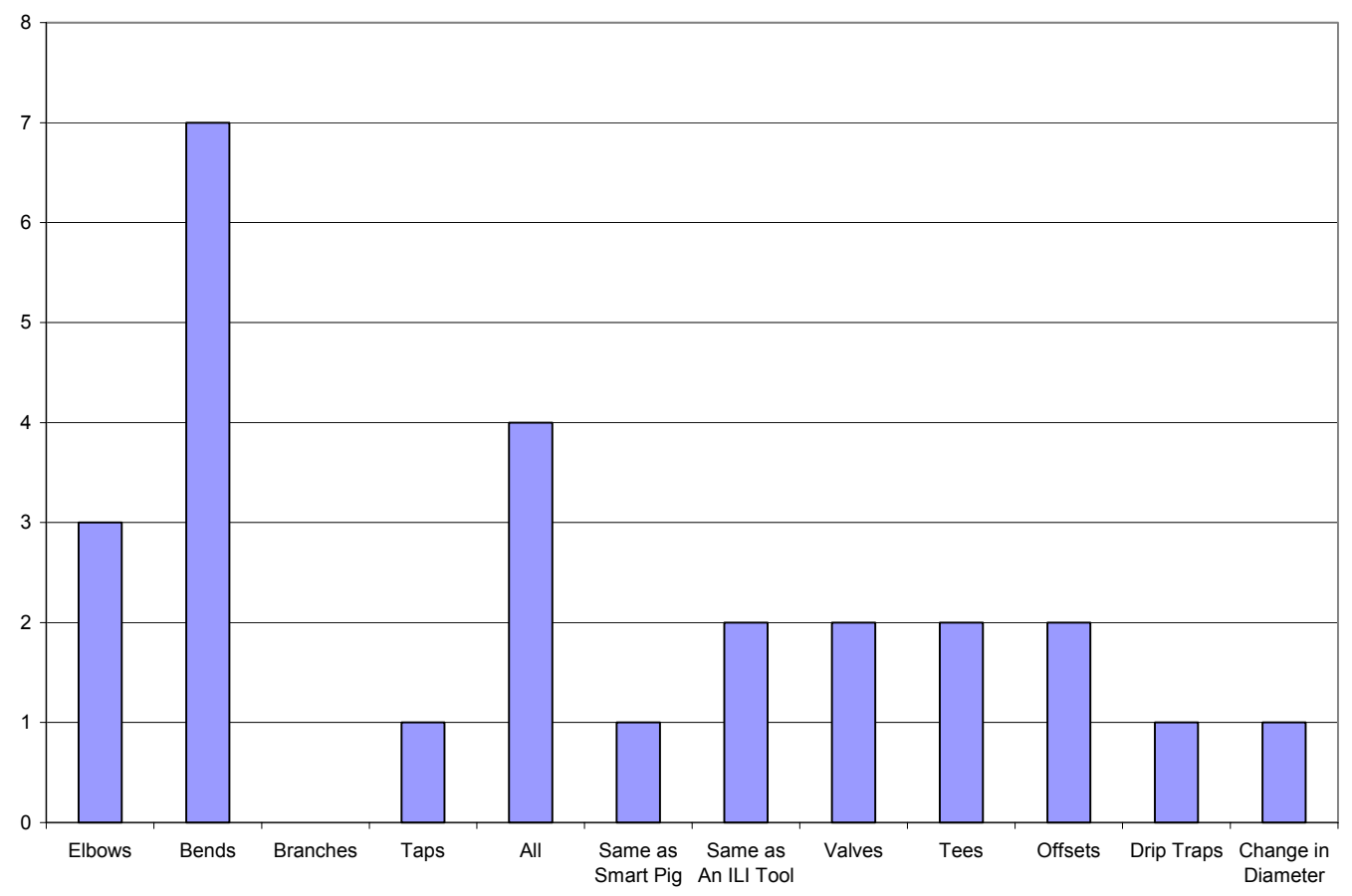

Figure 8 - Cost Comparative Breakpoint for Internal Repair

- Case by case basis

- $\$ 1,000 / 0.3 \mathrm{~m}(\$ 1,000 / \mathrm{ft}$.) is the benchmark for internal repair as this is the cost for HDD

- Road crossing/HDD cost is $\$ 50,000$ to $\$ 1,000,000$ depending on pipe size \& distance

- $\$ 25,000$ per repair site

- $\$ 30,000-\$ 60,000$ per repair site

- $\$ 50,000$ - $\$ 70,000$ per repair site

- $\$ 200,000$ per repair site

- Permanent repair less up to $\$ 1,000,000$

- Twice the cost of conventional repair

- Half the cost of conventional repair 
Figure 9 - Estimated Number of Internal Repairs Required Per Year

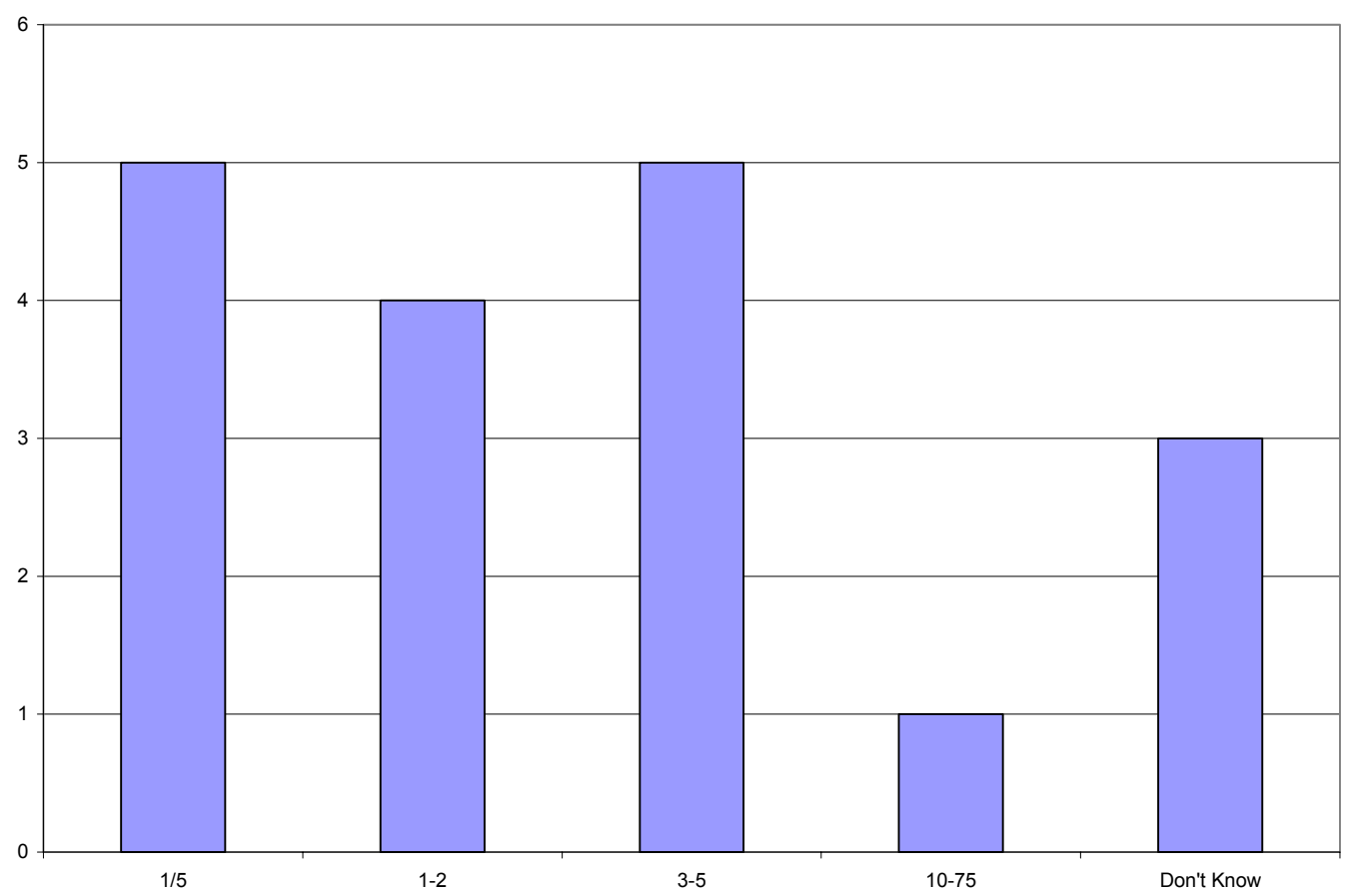

Figure 10 - Importance of Repair While Pipeline Remains In Service

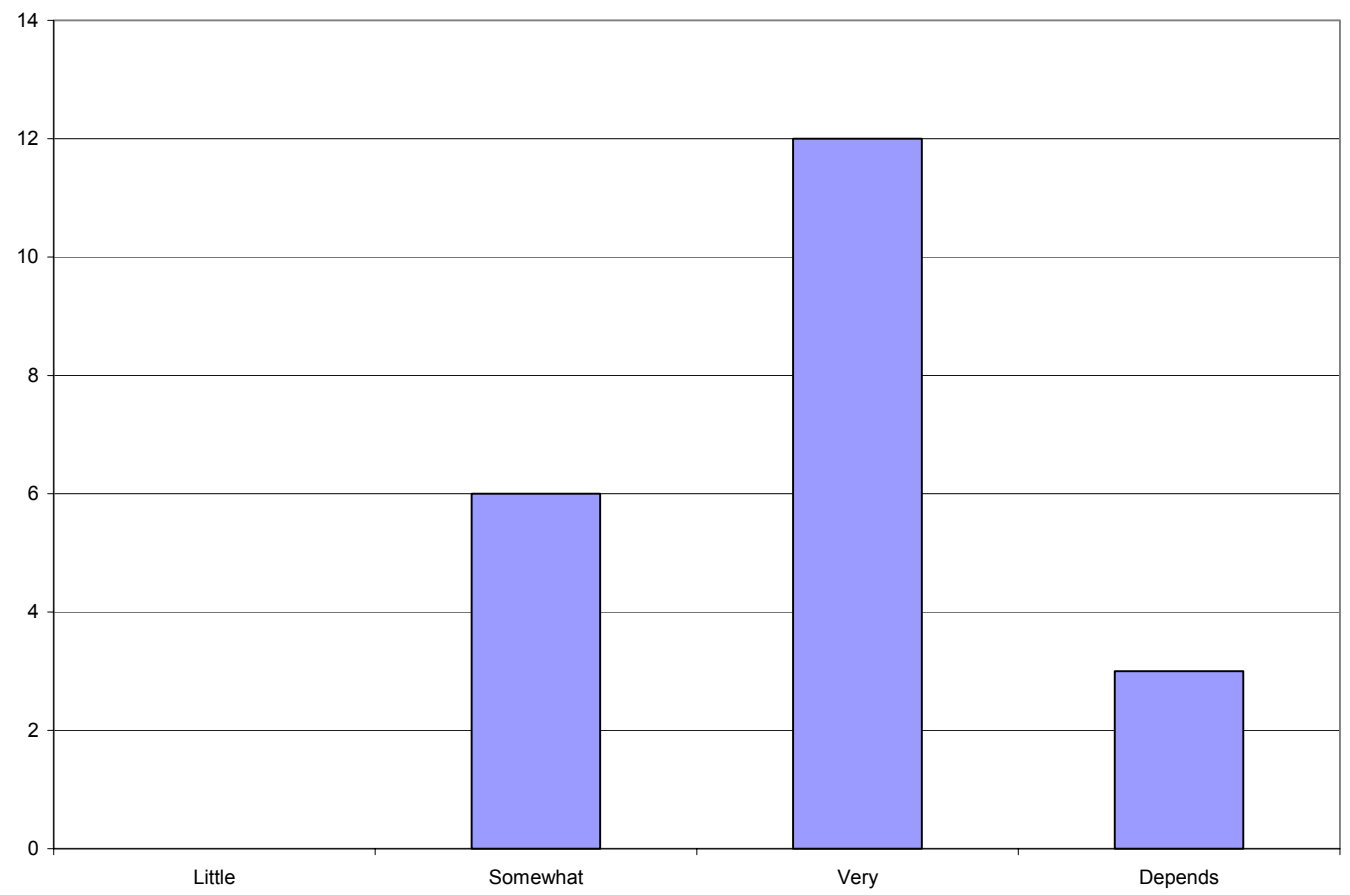


Figure 11 - Still Attractive if Pipeline Must be Shut Down (Depressurized and Evacuated)

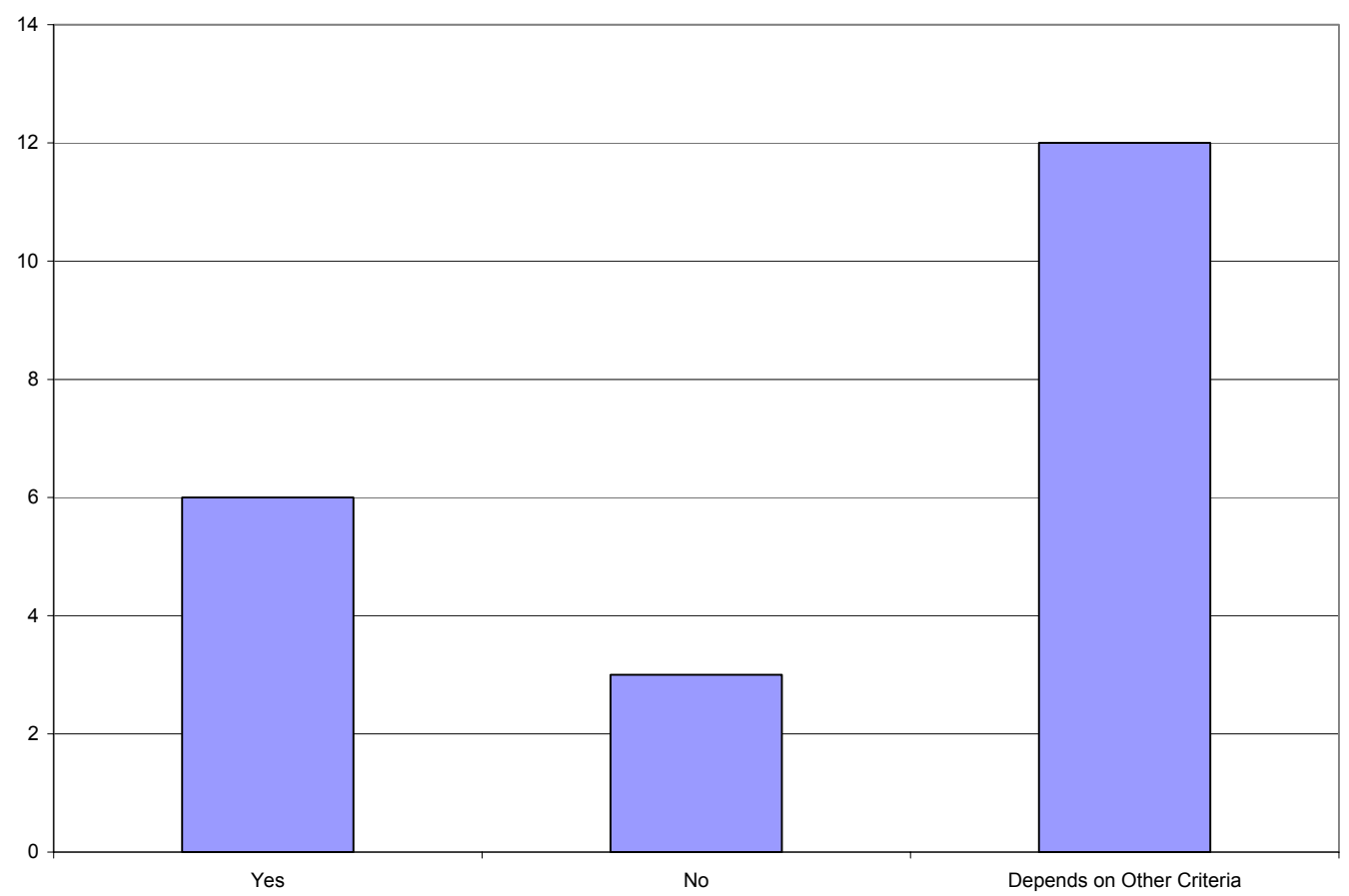

Figure 12 - Still Attractive if Pipeline Must be Depressurized but Not Evacuated

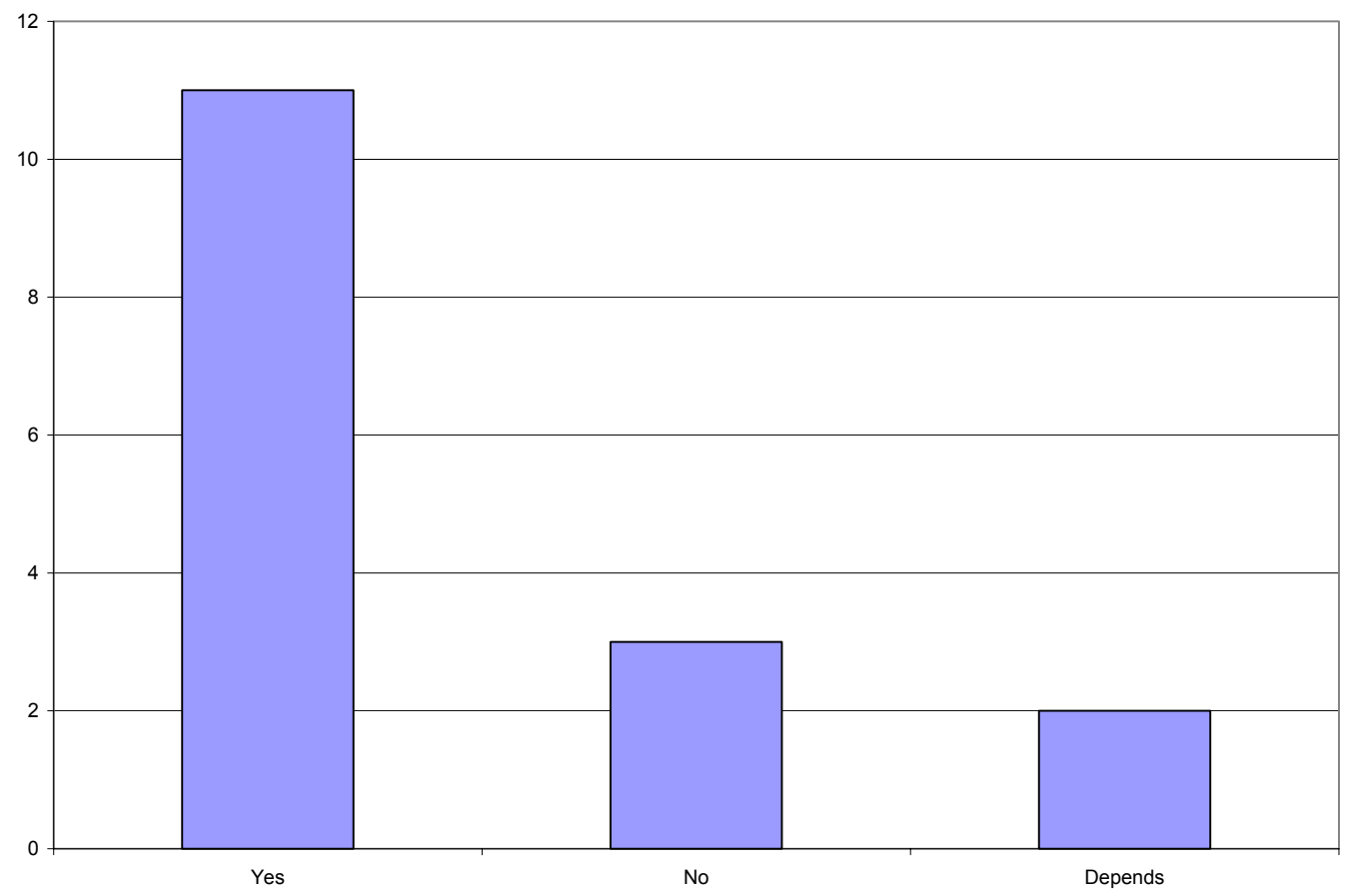


Figure 13 - Still Attractive if Pipeline Must be Out of Service but Pressurized

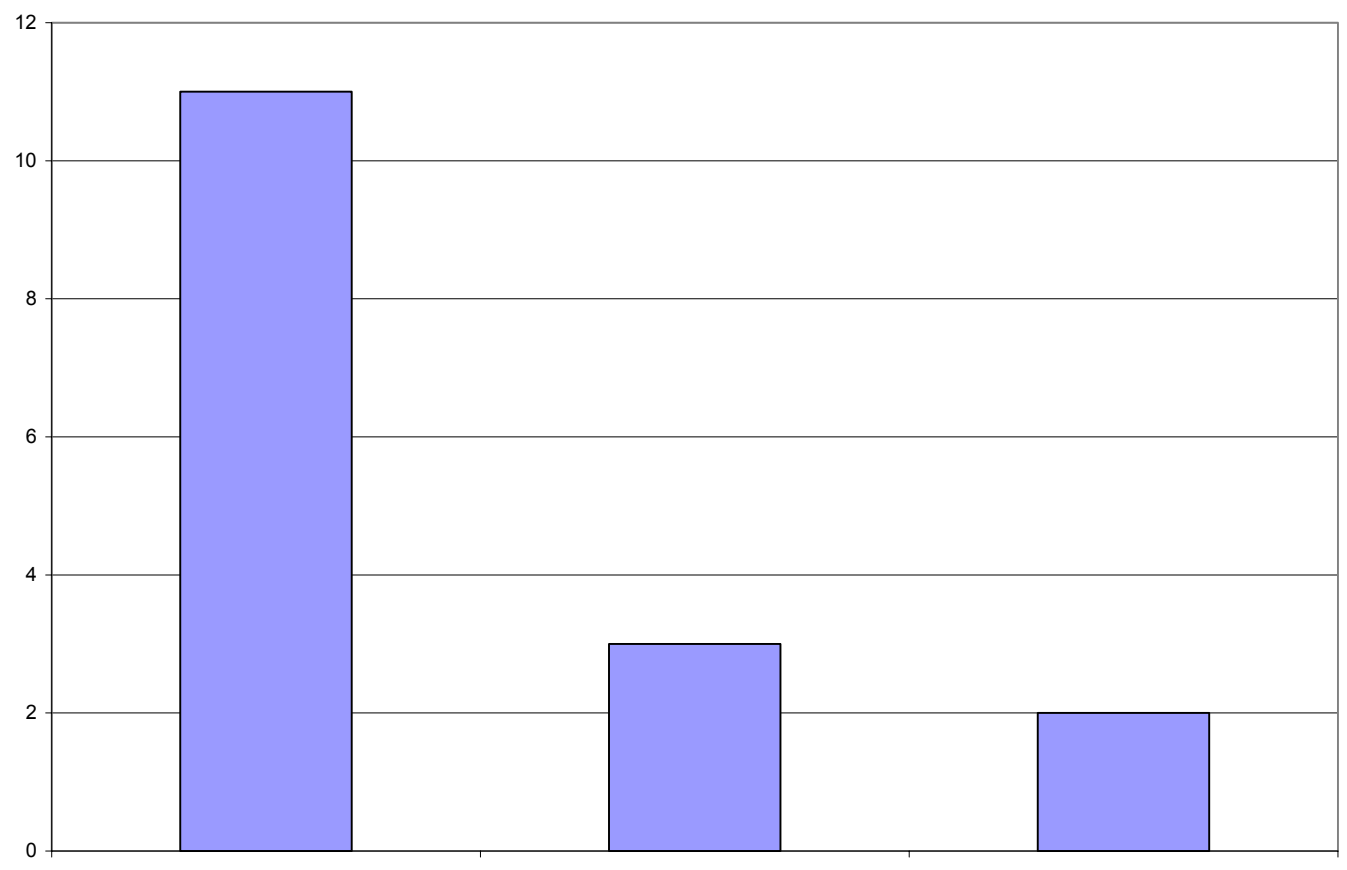

Yes

No

Depends

Figure 14 - External Coatings Used

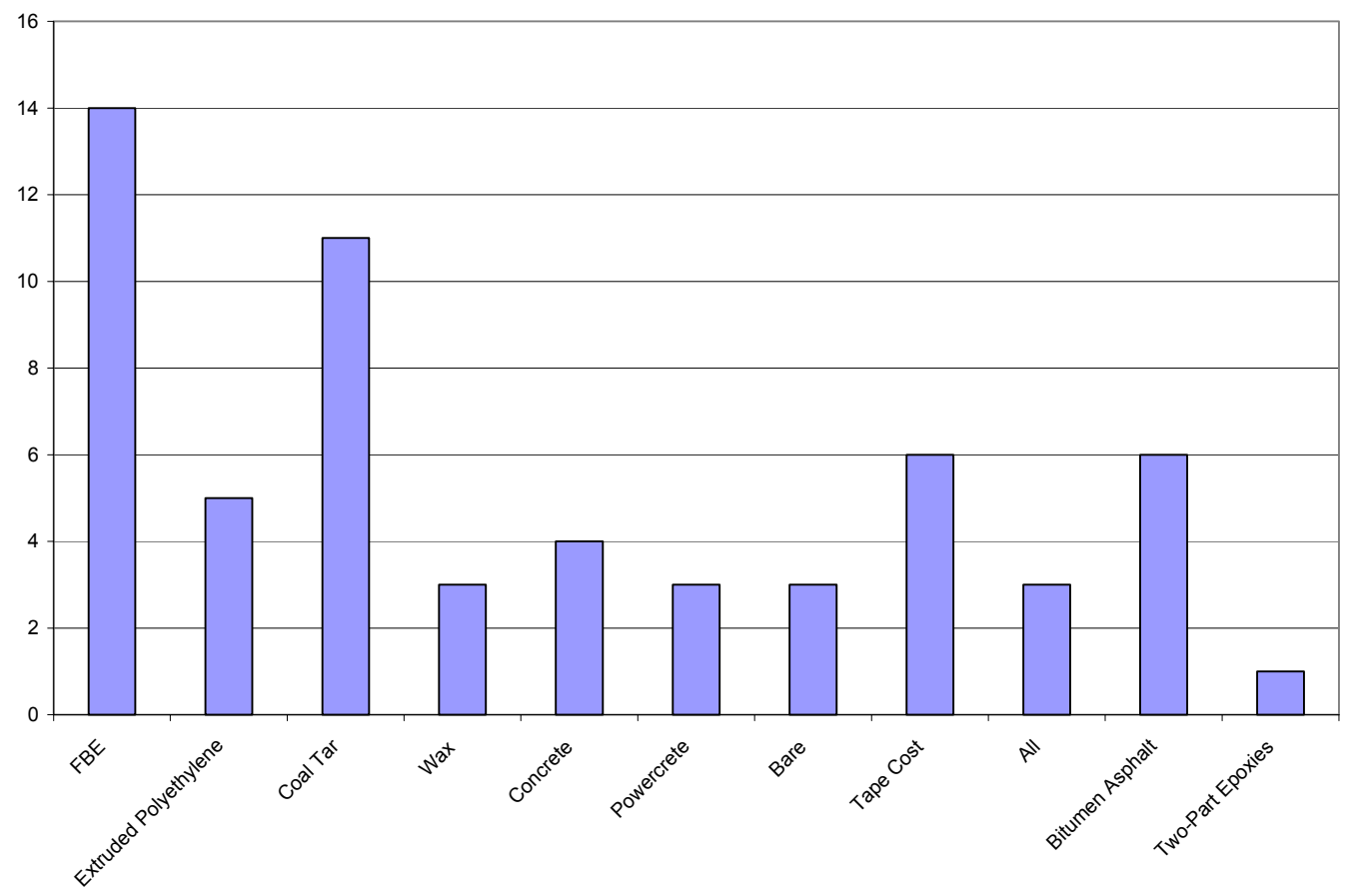


Figure 15 - Maintenance on Coating Integrity

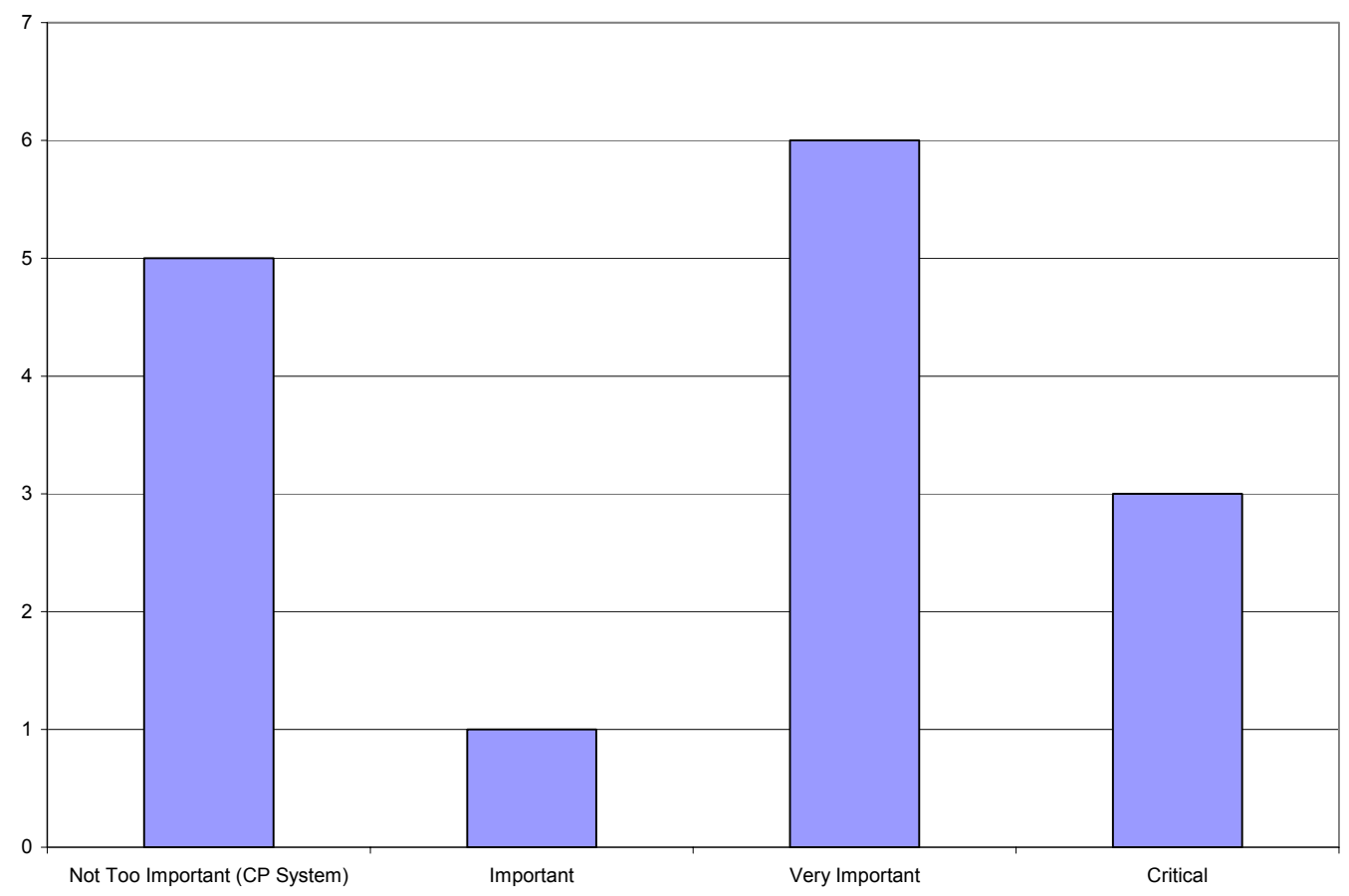

Figure 16 - Is CP System Capable of Compensating for Small Coating Breaches

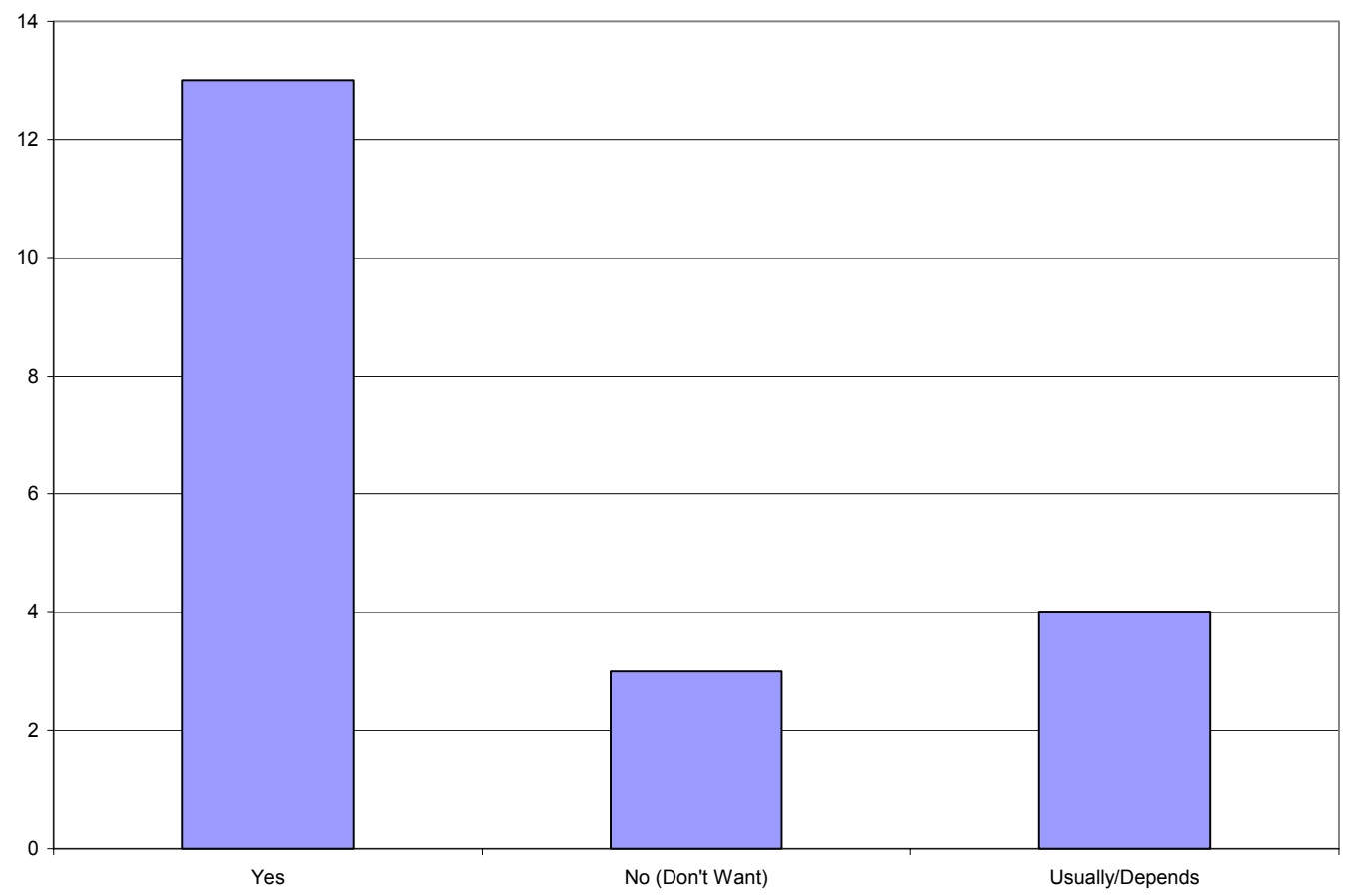


Figure 17 - Inspectable by Pigging

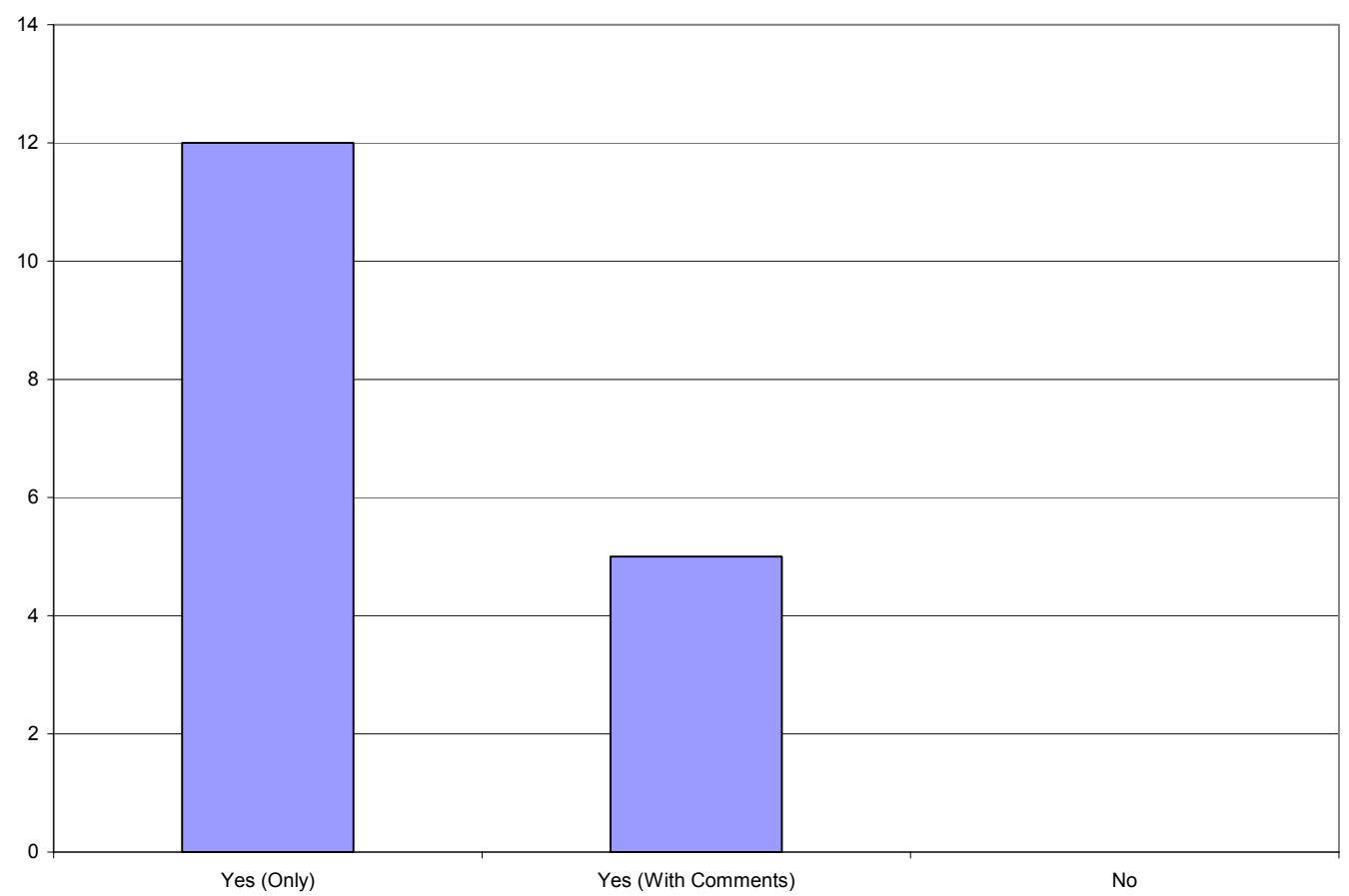

Figure 18 - How Far Could the Repair Protrude Into Pipe Before Interference

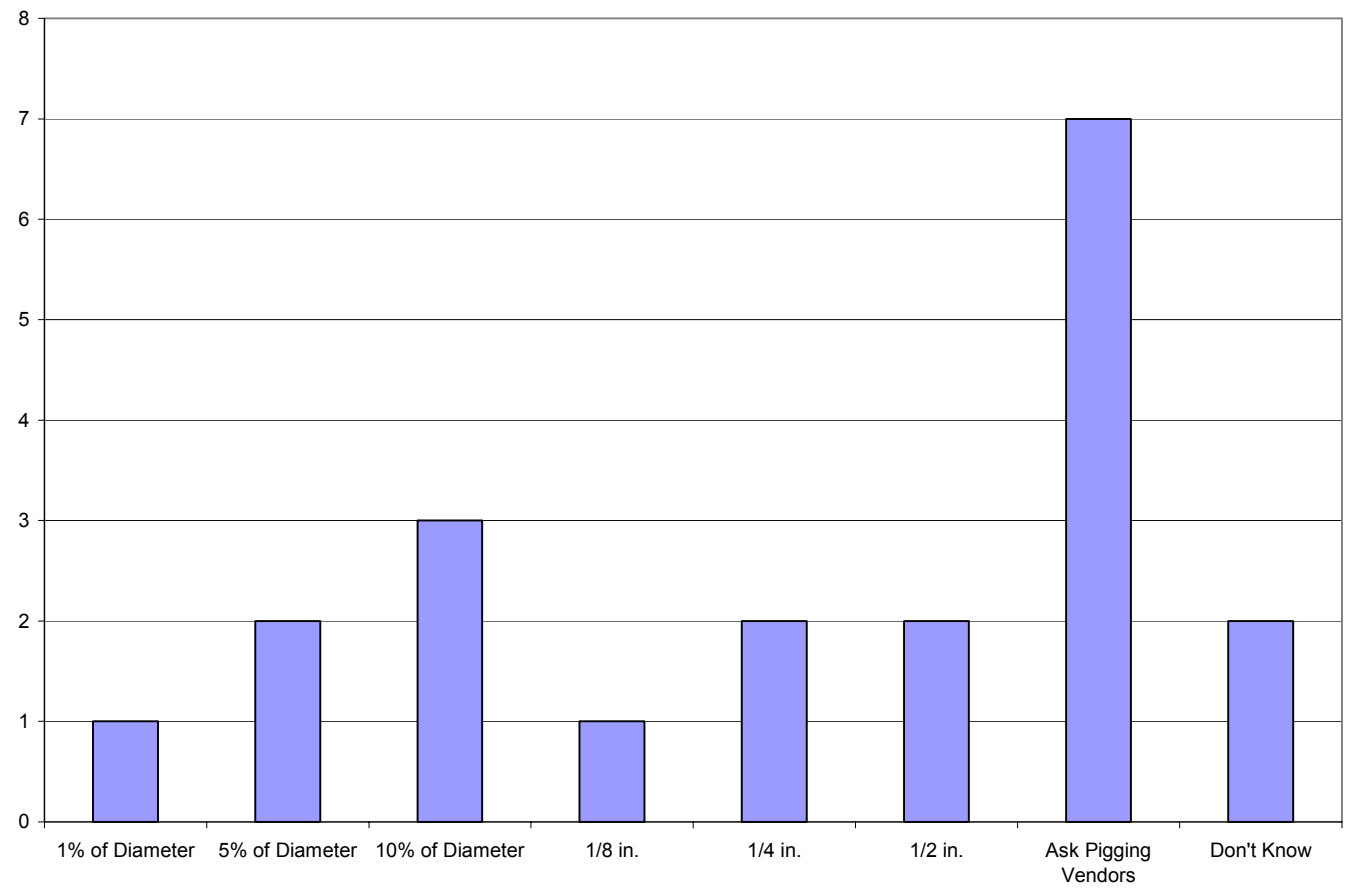


Figure 19 - NDE Required for Repair to an Existing Weld

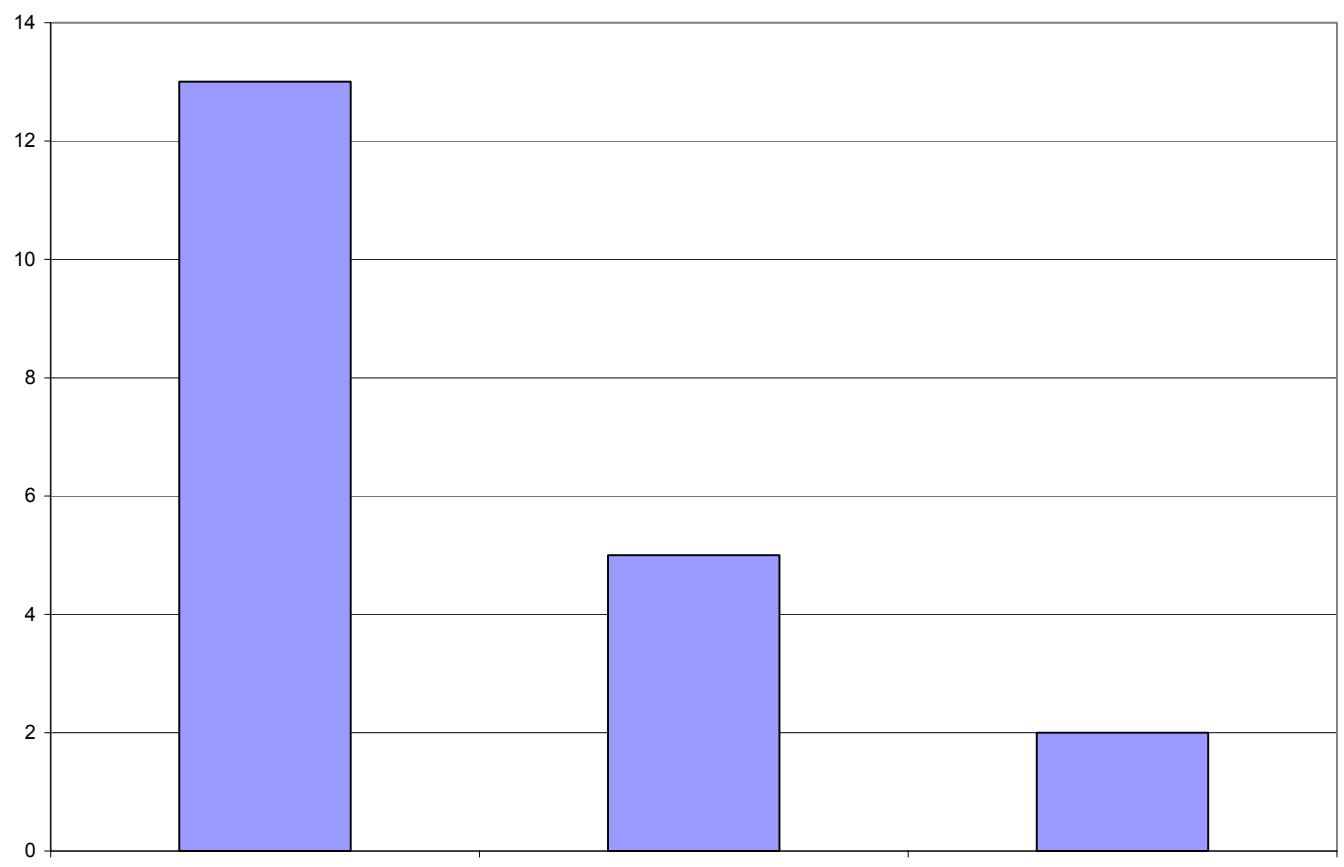

RT Only

RT or UT

RT or MPI

Figure 20 - NDE Required for Base Metal Repair

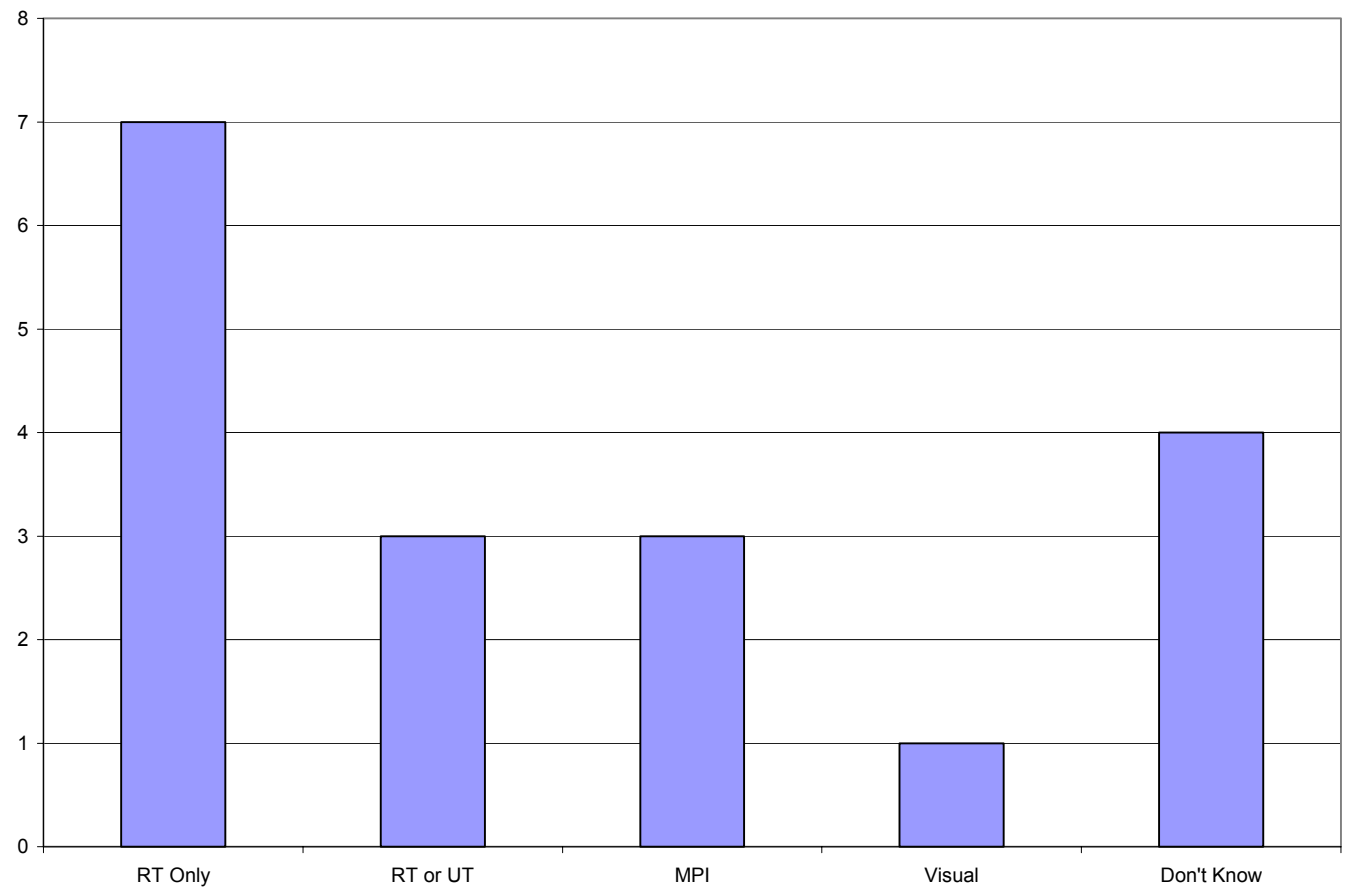


Figure 21 - Would Internal Repair be Attractive Even as a Temporary Repair?

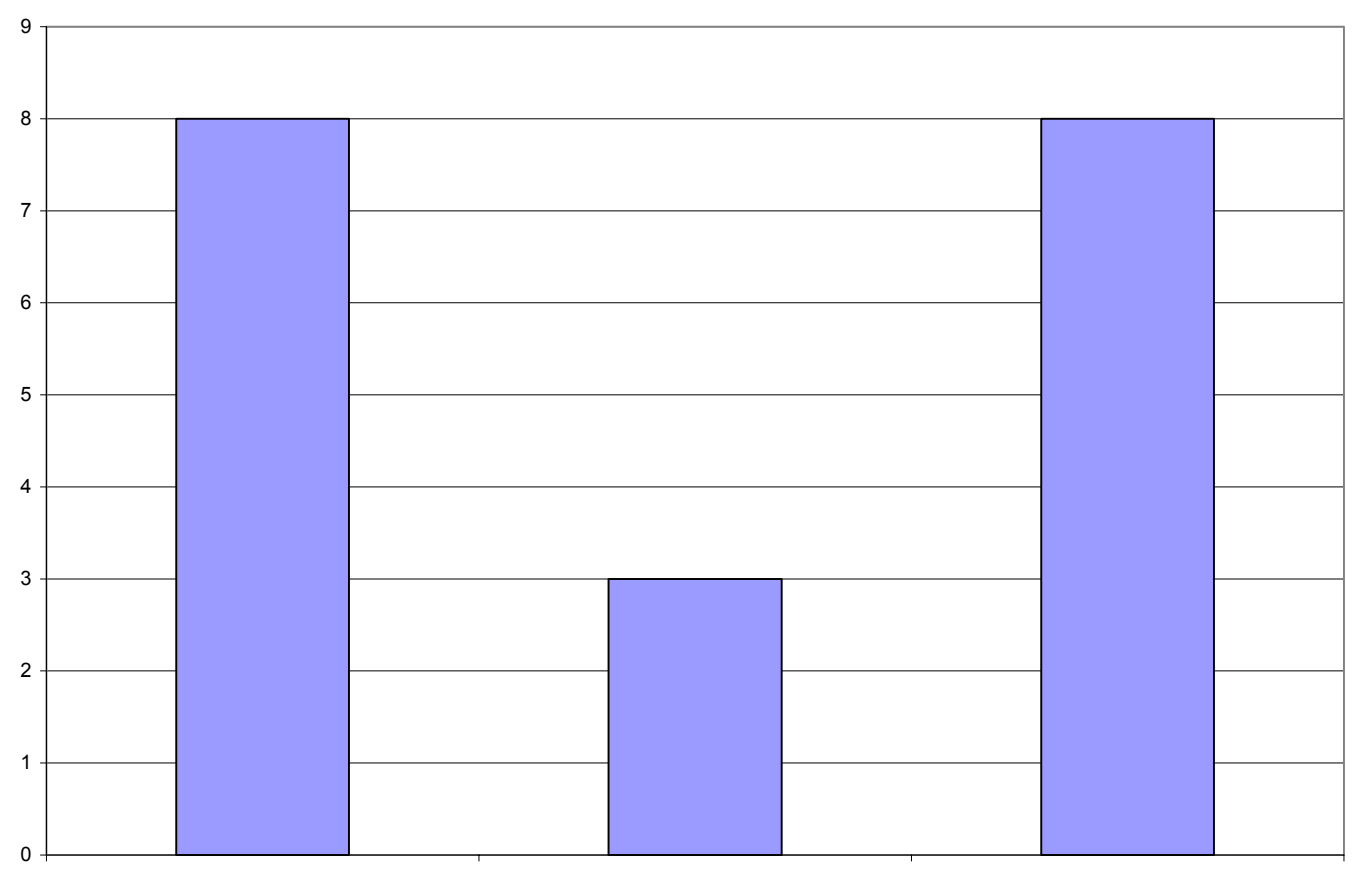

No

Yes (Only)

Yes (Qualified) 


\subsection{APPENDICES}




\section{APPENDIX A}

Survey and Cover Letter 
June 10, 2003

$<<<$ FIELD 1 $>>$

\section{EWI Project No. 46211GTH, "Internal Repair of Gas Transmission Pipelines - Survey of Operator Experience and Industry Needs"}

Dear $<<<$ FIELD 2 $>>$ :

Enclosed is a survey of operator experience and industry needs pertaining to internal repair of gas transmission pipelines.

EWI is conducting this survey as part of a project being funded by the National Energy Technology Laboratory. The objectives of the project are to evaluate, develop, demonstrate, and validate internal repair methods for pipelines; develop a functional specification for an internal pipeline repair system; and prepare a recommended practice for internal repair of pipelines.

One of the initial tasks of this project, co-funded by Pipelince Research Council International, involves conducting a survey to determine the repair needs and performance requirements for internal pipeline repairs. The purpose of this survey is to better understand the needs of the natural gas transmission industry regarding internal repair.

Please complete this survey at your earliest convenience. ${ }^{1}$ Your participation is greatly appreciated. If you have questions or require additional information, please contact me at 614688-5059 or bill_bruce@ewi.org

Sincerely,

Ian D. Harris and William A. Bruce, P.E.

Principal Engineers

Arc Welding, Automation and Materials

Enclosure

\footnotetext{
${ }^{1}$ A copy of this survey was also sent to $<<<$ FIELD 3 $>>>$ at your company. You may want to coordinate your response.
} 
Project No. 46211GTH

on

Internal Repair of Gas Transmission Pipelines - Survey of Operator Experience and Industry Needs

for

\section{National Energy Technology Laboratory}

Morgantown, WV

June 10, 2003

\section{EWI}

1250 Arthur E. Adams Drive

Columbus, $\mathrm{OH} 43221$ 


\section{Internal Repair of Gas Transmission Pipelines - Survey of Operator Experience and Industry Needs}

\subsection{Introduction}

A repair method that can be applied from the inside of a gas transmission pipeline (i.e., a trenchless repair) is an attractive alternative to conventional repair methods since the need to excavate the pipeline is precluded. This is particularly true for pipelines in environmentally sensitive and highly populated areas. Several repair methods that are commonly applied from the outside of the pipeline are, in theory, directly applicable from the inside. However, issues such as development of the required equipment to perform repairs remotely and mobilization of equipment through the pipeline to areas that require repair need to be addressed. Several additional repair methods that are commonly applied to other types of pipelines (gas distribution lines, water lines, etc.) also have potential applicability for internal repair of gas transmission pipelines. Many of these require further development to meet the requirements for repair of gas transmission pipelines. The purpose of this survey is to better understand the needs of the natural gas transmission industry regarding internal repair.

\subsection{Instructions}

Please respond as completely as possible to as many questions as possible. Space is also provided for any comments that you may have.

\subsection{Survey}

\section{Part 1 - Currently-Used Repair Methods}

1. Has your company experienced degradation (corrosion, cracking, etc) of a transmission line?

If so, describe the corrective actions your company has taken due to degradation of transmission pipelines, especially repair or replacement actions?

2. What specific repair methods would typically be used to repair different types of degradation?

3. What criteria (including ease of pipe access) affect choice of the specific repair method to be used? 
Comments pertaining to currently-used repair methods -

\section{Part 2 - Use/Potential Use of Internal Repair}

1. Has your company attempted repair of a transmission line from inside the pipe?

If so, describe the repair(s)

2. There are many factors that affect the decision to repair or replace pipe. What circumstances would favor performing a repair from inside the pipe using only one or two excavations rather than excavating the entire length of pipe?

3. If the technology were available to perform a repair from the inside, would your company consider using the technology?

If so, for what application(s) - e.g., specific geographic locations and special situations?

4. At least one excavation will be required to insert the internal repair device into the pipe. From this excavation, the repair device could be travel in each direction from the excavation. About how far from the insertion point should the repair device be able to travel?

In what range of pipe diameters should the repair device be capable of operation?

5. What potential obstructions such as elbows, bends, branches, and taps should the repair system be able to negotiate?

6. For the situations described in Question \#3, at what approximate cost would an internal repair method become competitive with existing repair options?

7. Have new regulatory requirements created a need to improve the fitness for service of existing transmission lines via localized repair or removal of conditions which are acceptable under previous criteria?

8. What is the estimated number of repairs per year which could potentially be performed by internal repair in your company for the reasons discussed in Questions \#3 and 7 ?

Comments pertaining to the use/potential use of internal repair - 


\section{Part 3 - Need for In-Service Internal Repair}

1. How important is the ability to perform a repair from the inside the pipe while the pipeline remains in service?

2. Would internal repair remain attractive if it was necessary to completely shut down the pipeline (depressurized and evacuated) during the repair?

Depressurized but not evacuated?

Out of service (no flow) but remain pressurized?

Comments pertaining to the need for in-service internal repair -

\section{Part 4 - Applicable Types of Damage}

1. What types of external coatings would be found on transmission lines owned by your company?

2. If a repair involving welding from the inside was performed, how important is it to preserve the integrity of the coating?

Is your cathodic protection system capable of compensating for relatively small breaches in the coating?

Comments pertaining to applicable types of damage -

\section{Part 5 - Operational and Performance requirements for Internal Repairs}

1. Two general categories of repairs are being considered, (1) using weld metal to restore a surface and (2) installing an internal sleeve, either metallic or nonmetallic, to provide structural reinforcement of leak tightness. Is it important that the line remain inspectable by pigging after repair?

About how far could the repair protrude into the pipe before it would interfere with pigging?

2. What NDE would your utility require for a repair to an existing longitudinal or circumferential weld? 
Could a visual or magnetic particle examination be substituted for radiography in these special circumstances?

What NDE would your utility require for a welded repair to base metal (e.g. corrosion pitting)?

3. Would the use of internal repair be attractive even if it were considered a temporary repair

Comments pertaining to operational and performance requirements for internal repairs -

\section{Part 6 - General Comments}

Please provide any general comments that you may have. For example, comments on a acceptable range of commercial pricing for such a system would be useful (as distinct from a repair cost in question 6 of Part 2.) 


\section{APPENDIX B}

Lists of PRCI Member and Other Gas Transmission Companies Including Contact Name, Email, and Telephone Contact Information Generated for the Survey 


\section{Members of the Pipeline Research Council International Email Contacts for Survey}

(As of 7/9/03 Email of main POC \{when determined\} for multiple listings, or single listings on Materials Committee)

\begin{tabular}{|c|c|}
\hline Organization & POC Email Address \\
\hline Advantica Technologies Ltd & bob.andrews@advanticatech.com \\
\hline 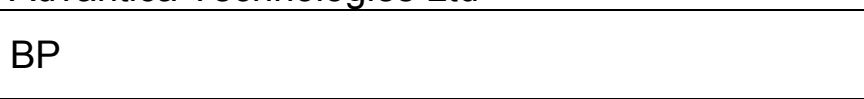 & $\begin{array}{l}\text { moskowln@bp.com, moredh@bp.com } \\
\text { hammondj3@bp.com, }\end{array}$ \\
\hline Buckeye Pipe Line Company & wshea@buckeye.com \\
\hline Chevron Texaco Pipeline Company & GBKO@ChevronTexaco.com \\
\hline CMS Panhandle Companies & smgallagher@cmsenergy.com \\
\hline Colonial Pipeline Company & jgodfrey@colpipe.com \\
\hline Columbia Gas Transmission Co. & jswatzel@nisource.com \\
\hline ConocoPhillips & dave.ysebaert@conocophillips.com \\
\hline Consumers Energy & rswelsh@cmsenergy.com \\
\hline Dominion Transmission & brian_c_sheppard@dom.com \\
\hline Duke Energy Gas Transmission & scrapp@duke-energy.com \\
\hline El Paso Corporation & bennie.barnes@elpaso.com \\
\hline Enbridge Pipelines & scott.ironside@enbridge.com \\
\hline Enron Transportation Services Corp. & mcrump@enron.com \\
\hline Explorer Pipeline Company & jwenzell@expl.com \\
\hline ExxonMobil Pipeline Company & don.e.drake@exxonmobil.com \\
\hline Foothills Pipe Lines Ltd & jack.beattie@foothillspipe.com \\
\hline Gassco A.S. (Norway) & eh@gassco.no \\
\hline Gasum Oy (Finland) & ilkka.taka-aho@gasum.fi \\
\hline Gaz de France & gerard.jammes@gazdefrance.com \\
\hline Gulf South Pipeline & scott.williams@gulfsouthpl.com \\
\hline Marathon Ashland Pipe Line LLC & tlshaw@mapllc.com \\
\hline $\begin{array}{l}\text { N.V. Nederlandse Gasunie/Gastransport Services } \\
\text { (The Netherlands) }\end{array}$ & w.sloterdijk@gasunie.nl \\
\hline National Fuel Gas Supply Corporation & pustulkaj@natfuel.com \\
\hline Saudi Aramco & shuler.cox@aramco.com \\
\hline $\begin{array}{l}\text { Sempra Energy Utilities/Southern California Gas } \\
\text { Company }\end{array}$ & bamend@semprautilities.com \\
\hline Shell Pipeline Company LP & janiemeyer@shellopus.com \\
\hline Southern Natural Gas Company & george.benoit@elpaso.com \\
\hline TEPPCO & Iwmallett@teppco.com \\
\hline TransCanada PipeLines Limited & david_dorling@transcanada.com \\
\hline Transco (UK) & jeremy.bending@uktransco.com \\
\hline TransGas & btorgunrud@transgas.com \\
\hline Williams Gas Pipeline & Thomas.R.Odom@Williams.com \\
\hline
\end{tabular}




\section{Members of the Pipeline Research Council International Contact Names and Phone Numbers}

(As of $7 / 9 / 03$ )

\begin{tabular}{|c|c|c|}
\hline Organization & POC Name & Phone Number \\
\hline Advantica Technologies Ltd & Bob Andrews & 011441509282749 \\
\hline $\mathrm{BP}$ & John Hammond & 011441932775909 \\
\hline $\mathrm{BP}$ & David Moore & 9075644190 \\
\hline $\mathrm{BP}$ & Larry Moskowitz & 2813662924 \\
\hline Buckeye Pipe Line Company & William Shea & 6102544650 \\
\hline Chevron Texaco Pipeline Company & George Kohut & 5102423245 \\
\hline CMS Panhandle Companies & Scott Gallagher & 7139897444 \\
\hline Colonial Pipeline Company & John Godfrey & 6787622217 \\
\hline Columbia Gas Transmission Co. & Jim Swatzel & 3043572797 \\
\hline ConocoPhillips & Dave Ysebaert & 2812932969 \\
\hline Consumers Energy & Robert Welsh & 5177881928 \\
\hline Dominion Transmission & Brian Sheppard & 3046273733 \\
\hline Duke Energy Gas Transmission & Steve Rapp & 7136276394 \\
\hline El Paso Corporation & Bennie Barnes & 7195204677 \\
\hline Enbridge Pipelines & Scott Ironside & 7804205267 \\
\hline Enron Transportation Services Corp. & Michael Crump & 7133451623 \\
\hline Explorer Pipeline Company & Jeff Wenzell & 9184935140 \\
\hline ExxonMobil Pipeline Company & Don Drake & 7136562288 \\
\hline Foothills Pipe Lines Ltd & Jack Beattie & 4032944143 \\
\hline Gassco A.S. (Norway) & Egil Hurloe & 0114752812500 \\
\hline Gasum Oy (Finland) & Ilkka Taka-Aho & 011358204478653 \\
\hline Gaz de France & Gerard Jammes & 0113349225419 \\
\hline Gulf South Pipeline & Scott Williams & 7135445220 \\
\hline Marathon Ashland Pipe Line LLC & Thomas Shaw & 4194214002 \\
\hline N.V. Nederlandse Gasunie/Gastransport & Wytze Sloterdijk & 01131505212674 \\
\hline National Fuel Gas Supply Corporation & John Pustulka & 7168577909 \\
\hline Saudi Aramco & Shuler Cox & 01196638746664 \\
\hline Sempra Energy Utilities/Southern Cal Gas & Bill Amend & 2132445277 \\
\hline Shell Pipeline Company LP & John Niemeyer & 7132411856 \\
\hline Southern Natural Gas Company & George Benoit & 8325284244 \\
\hline TEPPCO & Leonard Mallett & 7137593615 \\
\hline TransCanada PipeLines Limited & David Dorling & 4039488147 \\
\hline Transco (UK) & Jeremy Bending & 011441689881479 \\
\hline TransGas & Brian Torgunrud & 3067779357 \\
\hline Williams Gas Pipeline & Thomas Odom & 2706886964 \\
\hline
\end{tabular}




\title{
Other Natural Gas Pipeline Operating Companies - Email Contacts
}

\author{
(As of $7 / 9 / 03$ )
}

\begin{tabular}{|c|c|c|}
\hline Organization & Location & Email Address \\
\hline Algonquin Gas Transmission Co. & Duke Energy & scrapp@duke-energy.com \\
\hline Algonquin LNG, Inc. & Duke Energy & scrapp@duke-energy.com \\
\hline Alliance Pipeline Ltd. & & arti.bhatia@alliance-pipeline.com \\
\hline ANR Pipeline Co. & El Paso & george.benoit@elpaso.com \\
\hline ANR Storage Co. & El Paso & george.benoit@elpaso.com \\
\hline Black Marlin Pipeline Co. & Williams & Thomas.R.Odom@Williams.com \\
\hline Blue Lake Gas Storage Co. & El Paso & robert.white@elpaso.com \\
\hline Canyon Creek Compression Co. & K. Morgan (KM) & mark_mayworn@kindermorgan.com \\
\hline Carnegie Interstate Pipeline Co. & Equitrans & amurphy@eqt.com \\
\hline Chandeleur Pipe Line Co. & ChevronTexaco & GBKO@ChevronTexaco.com \\
\hline Colorado Interstate Gas Co. & El Paso & bennie.barnes@elpaso.com \\
\hline Columbia Gas Transmission Corp. & Columbia & jswatzel@nisource.com \\
\hline Columbia Gulf Transmission Co. & Columbia & jswatzel@nisource.com \\
\hline Cove Point LNG, L.P. & Dominion & brian_c_sheppard@dom.com \\
\hline Crossroads Pipeline Co. & Columbia & jswatzel@nisource.com \\
\hline Discovery Gas Transmission LLC & Williams & Thomas.R.Odom@Williams.com \\
\hline Dynegy Midstream Pipeline, Inc. & & rich.a.mueller@dynegy.com \\
\hline East Tennessee Natural Gas Co. & Duke Energy & scrapp@duke-energy.com \\
\hline Egan Hub Partners, L.P. & Duke Energy & scrapp@duke-energy.com \\
\hline El Paso Natural Gas Co. & El Paso & bennie.barnes@elpaso.com \\
\hline El Paso Field Services & El Paso & pat.davis@elpaso.com \\
\hline Energy East & & spmartin@energyeast.com \\
\hline EPGT Texas Pipeline, L.P. & El Paso & pat.davis@elpaso.com \\
\hline Equitrans, Inc. & & amurphy@eqt.com \\
\hline Florida Gas Transmission Co. & Enron & mcrump@enron.com \\
\hline Granite State Gas Transmission, Inc. & Columbia & jswatzel@nisource.com \\
\hline Great Lakes Gas Transmission, L.P. & & rgrondin@glgt.com \\
\hline Gulf South Pipeline & & scott.williams@gulfsouthpl.com \\
\hline Gulf States Transmission Corp. & El Paso & george.benoit@elpaso.com \\
\hline High Island Offshore System & El Paso & george.benoit@elpaso.com \\
\hline Iroquois Gas Transmission System & & ben_gross@iroquois.com \\
\hline Kansas Pipeline Co. & $\begin{array}{c}\text { Midcoast Energy } \\
\text { Enbridge }\end{array}$ & scott.ironside@enbridge.com \\
\hline Kentucky West Virginia Gas Co. & Equitrans & amurphy@eqt.com \\
\hline Kern River Gas Transmission Co. & Williams & Thomas.R.Odom@Williams.com \\
\hline Keyspan Energy & & psheth@keyspanenergy.com \\
\hline KM Interstate Gas Transmission Co. & KM & mark_mayworn@kindermorgan.com \\
\hline KN Wattenberg Transmission & $\mathrm{KM}$ & mark_mayworn@kindermorgan.com \\
\hline Maritimes \& Northeast Pipeline L.L.C. & Duke Energy & scrapp@duke-energy.com \\
\hline Michigan Gas Storage Co. & $\begin{array}{l}\text { Consumers } \\
\text { Energy }\end{array}$ & rswelsh@cmsenergy.com \\
\hline Midwestern Gas Transmission Co. & Enron & mcrump@enron.com \\
\hline
\end{tabular}




\begin{tabular}{|c|c|c|}
\hline Organization & Location & Email Address \\
\hline MIGC, Inc. & Western Gas & jcurtis@westerngas.com \\
\hline Mississippi River Transmission Corp. & $\begin{array}{l}\text { CenterPoint } \\
\text { Energy }\end{array}$ & scott.mundy@centerpointenergy.com \\
\hline Mojave Pipeline Co. & El Paso & bennie.barnes@elpaso.com \\
\hline National Fuel Gas Supply Corp. & & pustulkaj@natfuel.com \\
\hline Natural Gas Pipeline Co. of America & $\mathrm{KM}$ & mark_mayworn@kindermorgan.com \\
\hline Nora Transmission Co. & Equitrans & amurphy@eqt.com \\
\hline North Carolina Natural Gas & $\begin{array}{l}\text { Carolina Power \& } \\
\text { Light }\end{array}$ & Theodore.hodges@cplc.com \\
\hline Northern Border Pipeline Co. & Enron & mcrump@enron.com \\
\hline Northern Natural Gas Co. & $\begin{array}{l}\text { Midamerican } \\
\text { Energy }\end{array}$ & paul.fuhrer@nngco.com \\
\hline Northwest Pipeline Corp. & Williams & Thomas.R.Odom@Williams.com \\
\hline Overthrust Pipeline Co. & Questar & ronji@questar.com \\
\hline Oncor Gas & & mrothba1@oncorgroup.com \\
\hline Ozark Gas Transmission System & & strawnlw@oge.com \\
\hline Paiute Pipeline Co. & Southwest Gas & jerry.schmitz@swgas.com \\
\hline Panhandle Eastern Pipe Line Co. & CMS & smgallagher@cmsenergy.com \\
\hline Petal Gas Storage Co. & El Paso & bennie.barnes@elpaso.com \\
\hline $\begin{array}{l}\text { PG\&E Gas Transmission-Northwest } \\
\text { Corp. }\end{array}$ & PG\&E & WJH7@pge.com \\
\hline $\begin{array}{l}\text { PG\&E Gas Transmission-Northwest } \\
\text { Corp. }\end{array}$ & $P G \& E$ & ADE1@pge.com \\
\hline Questar Pipeline Co. & Questar & ronji@questar.com \\
\hline Reliant Energy Gas Transmission Co. & $\begin{array}{l}\text { CenterPoint } \\
\text { Energy }\end{array}$ & scott.mundy@centerpointenergy.com \\
\hline Sabine Pipe Line Co. & ChevronTexaco & GBKO@ChevronTexaco.com \\
\hline Sea Robin Pipeline Co. & CMS & smgallagher@cmsenergy.com \\
\hline Shell Offshore Pipelines & Shell & janiemeyer@shellopus.com \\
\hline Southern Natural Gas Co. & El Paso & george.benoit@elpaso.com \\
\hline Southwest Gas Corp. & & jerry.Schmitz@swgas.com \\
\hline Southwest Gas Storage Co. & CMS & smgallagher@cmsenergy.com \\
\hline Steuben Gas Storage Co. & ANR/Arlington & george.benoit@elpaso.com \\
\hline Tennessee Gas Pipeline Co. & El Paso & george.benoit@elpaso.com \\
\hline Texas Eastern Transmission Corp. & Duke Energy & scrapp@duke-energy.com \\
\hline Texas Gas Transmission Corp. & Williams & Thomas.R.Odom@Williams.com \\
\hline Total Peaking LLC & Energy East & spmartin@energyeast.com \\
\hline Trailblazer Pipeline Co. & $\mathrm{KM}$ & mark_mayworn@kindermorgan.com \\
\hline TransColorado Gas Transmission Co. & KM & mark_mayworn@kindermorgan.com \\
\hline Transcontinental Gas Pipe Line Corp. & Williams & Thomas.R.Odom@Williams.com \\
\hline Transwestern Pipeline Co. & Enron & mcrump@enron.com \\
\hline Trunkline Gas Co. & CMS & smgallagher@cmsenergy.com \\
\hline Trunkline LNG Co. & CMS & smgallagher@cmsenergy.com \\
\hline Tuscarora Gas Transmission Co. & & Icherwenuk@tuscaroragas.com \\
\hline TXU Gas/TXU Lone Star Pipeline & TXU Gas & mrothba1@oncorgroup.com \\
\hline Vector Pipeline & Enbridge & scott.ironside@enbridge.com \\
\hline Venice Gathering System, L.L.C. & Dynergy & rich.a.mueller@dynegy.com \\
\hline
\end{tabular}




\begin{tabular}{|l|c|l|}
\hline Organization & Location & Email Address \\
\hline Viking Gas Transmission Co. & $\begin{array}{c}\text { Northern Border } \\
\text { (Enron) }\end{array}$ & mcrump@enron.com \\
\hline Williams Gas Pipelines Central, Inc. & Williams & Thomas.R.Odom@Williams.com \\
\hline Williston Basin Interstate Pipeline Co. & & keith.seifert@wbip.com \\
\hline Wyoming Interstate Co., Ltd. & El Paso & bennie.barnes@elpaso.com \\
\hline Young Gas Storage Co., Ltd. & El Paso & bennie.barnes@elpaso.com \\
\hline
\end{tabular}




\section{Other Natural Gas Pipeline Operating Companies Contact Names and Phone Numbers}

(As of $7 / 9 / 03$ )

\begin{tabular}{|c|c|c|}
\hline Organization & POC Name & Phone Number \\
\hline Algonquin Gas Transmission Co. & Steve Rapp & 7136276394 \\
\hline Algonquin LNG, Inc. & Steve Rapp & 7136276394 \\
\hline Alliance Pipeline Ltd. & Arti Bhatia & 4035177727 \\
\hline ANR Pipeline Co. & George Benoit & 8325284244 \\
\hline ANR Storage Co. & George.Benoit & 8325284244 \\
\hline Black Marlin Pipeline Co. & Thomas Odom & 2706886964 \\
\hline Blue Lake Gas Storage Co. & Robert White & 2489944046 \\
\hline Canyon Creek Compression Co. K. Morgan & Mark Mayworn & 7133699347 \\
\hline Carnegie Interstate Pipeline Co. & Andy Murphy & 4122314888 \\
\hline Chandeleur Pipe Line Co. & George Kohut & 5102423245 \\
\hline Colorado Interstate Gas Co. & Bennie Barnes & 7195204677 \\
\hline Columbia Gas Transmission Corp. & Jim Swatzel & 3043572797 \\
\hline Columbia Gulf Transmission Co. & Jim Swatzel & 3043572797 \\
\hline Cove Point LNG Limited Partnership & Brian Sheppard & 3046273733 \\
\hline Crossroads Pipeline Co. & Jim Swatzel & 3043572797 \\
\hline Discovery Gas Transmission LLC & Thomas Odom & 2706886964 \\
\hline Dynegy Midstream Pipeline, Inc. & Rich Mueller & 7135073992 \\
\hline East Tennessee Natural Gas Co. & Steve Rapp & 7136276394 \\
\hline Egan Hub Partners, L.P. & Steve Rapp & 7136276394 \\
\hline El Paso Field Services & Pat Davis & 2105284244 \\
\hline El Paso Natural Gas Co. & Bennie Barnes & 7195204677 \\
\hline Energy East & Scott Martin & 6073472561 \\
\hline EPGT Texas Pipeline, L.P. & Pat Davis & 2105284244 \\
\hline Equitrans, Inc. & Andy Murphy & 4122314888 \\
\hline Florida Gas Transmission Co. & Michael Crump & 7133451623 \\
\hline Granite State Gas Transmission, Inc. & Jim Swatzel & 3043572797 \\
\hline Great Lakes Gas Transmission L.P. & Ryan Grondin & 3214391777 \\
\hline Gulf South Pipeline & Scott Williams & 7135445220 \\
\hline Gulf States Transmission Corp. & George Benoit & 8325284244 \\
\hline High Island Offshore System & George.Benoit & 8325284244 \\
\hline Iroquois Gas Transmission System, L.P. & Ben Gross & 2039257257 \\
\hline Kansas Pipeline Company & Scott Ironside & 7804205267 \\
\hline Kentucky West Virginia Gas Co. & Andy Murphy & 4122314888 \\
\hline Kern River Gas Transmission Co. & Thomas Odom & 2706886964 \\
\hline Keyspan Energy & Perry Sheth & 5165453844 \\
\hline KM Interstate Gas Transmission Co. & Mark Mayworn & 7133699347 \\
\hline KN Wattenberg Transmission & Mark Mayworn & 7133699347 \\
\hline Maritimes \& Northeast Pipeline L.L.C. & Steve Rapp & 7136276394 \\
\hline Michigan Gas Storage Co. & Robert Welsh & 5177881928 \\
\hline Midwestern Gas Transmission Co. & Michael Crump & 7133451623 \\
\hline MIGC, Inc. & John Curtis & \\
\hline
\end{tabular}




\begin{tabular}{|c|c|c|}
\hline Organization & POC Name & Phone Number \\
\hline Mississippi River Transmission Corp. & Scott Mundy & 3184293943 \\
\hline Mojave Pipeline Co. & Bennie Barnes & 7195204677 \\
\hline National Fuel Gas Supply Corp. & John Pustulka & 7168577909 \\
\hline Natural Gas Pipeline Co. of America & Mark Mayworn & 7133699347 \\
\hline Nora Transmission Co. & Andy Murphy & 4122314888 \\
\hline North Carolina Natural Gas & Ted Hodges & 9195466369 \\
\hline Northern Border Pipeline Co. & Michael Crump & 7133451623 \\
\hline Northern Natural Gas Co. & Paul Fuhrer & 4023987733 \\
\hline Northwest Pipeline Corp. & Thomas Odom & 2706886964 \\
\hline Oncor Gas & Mark Rothbauer & 2148755574 \\
\hline Overthrust Pipeline Co. & Questar & ronji@questar.com \\
\hline Ozark Gas Transmission System & Larry Strawn & 4055575271 \\
\hline Paiute Pipeline Co. & Jerry Schmitz & 7023652204 \\
\hline Panhandle Eastern Pipe Line Co. & Scott Gallagher & 7139897444 \\
\hline Petal Gas Storage Co. & Bennie Barnes & 7195204677 \\
\hline PG\&E Gas Transmission-Northwest Corp. & Bill Harris & 9259744030 \\
\hline PG\&E Gas Transmission-Northwest Corp. & Alan Eastman & 9259744312 \\
\hline Questar Pipeline Co. & Questar & ronji@questar.com \\
\hline Reliant Energy Gas Transmission Co. & Scott Mundy & 3184293943 \\
\hline Sabine Pipe Line Co. & George Kohut & 5102423245 \\
\hline Sea Robin Pipeline Co. & Scott Gallagher & 7139897444 \\
\hline Shell Offshore Pipelines & John Niemeyer & 7132411856 \\
\hline Southern Natural Gas Co. & George Benoit & 8325284244 \\
\hline Southwest Gas Corp. & Jerry Schmitz & 7023652204 \\
\hline Southwest Gas Storage Co. & Scott Gallagher & 7139897444 \\
\hline Steuben Gas Storage Co. & George Benoit & 8325284244 \\
\hline Tennessee Gas Pipeline Co. & George Benoit & 8325284244 \\
\hline Texas Eastern Transmission Corp. & Steve Rapp & 7136276394 \\
\hline Texas Gas Transmission Corp. & Thomas Odom & 2706886964 \\
\hline Total Peaking LLC & Scott Martin & 6073472561 \\
\hline Trailblazer Pipeline Co. & Mark Mayworn & 7133699347 \\
\hline TransColorado Gas Transmission Co. & Mark Mayworn & 7133699347 \\
\hline Transcontinental Gas Pipe Line Corp. & Thomas Odom & 2706886964 \\
\hline Transwestern Pipeline Co. & Michael Crump & 7133451623 \\
\hline Trunkline Gas Co. & Scott Gallagher & 7139897444 \\
\hline Trunkline LNG Co. & Scott Gallagher & 7139897444 \\
\hline Tuscarora Gas Transmission Co. & Les Cherwenuk & 7758343674 \\
\hline TXU Gas/TXU Lone Star Pipeline & Mark Rothbauer & 2148755574 \\
\hline Vector Pipeline & Scott Ironside & 7804205267 \\
\hline Venice Gathering System, L.L.C. & Rich Mueller & 3184293943 \\
\hline Viking Gas Transmission Co. & Michael Crump & 7133451623 \\
\hline Williams Gas Pipelines Central, Inc. & Thomas Odom & 2706886964 \\
\hline Williston Basin Interstate Pipeline Co. & Keith Seifert & 4063597223 \\
\hline Wyoming Interstate Company, Ltd. & Bennie Barnes & 7195204677 \\
\hline Young Gas Storage Company, Ltd. & Bennie Barnes & 7195204677 \\
\hline
\end{tabular}

